\title{
Inflexibly Enacted Traditional Masculinity Norms (IE-TMNs) and Their Impact on Adolescent and Young Adult Depression: The Hybrid Case Study of "Tommy"
}

\section{CHRISTOPHER DEWEY ${ }^{\mathrm{a}, \mathrm{b}, \mathrm{c}}$}

\author{
${ }^{\text {a }}$ Providence College Personal Counseling Center, Providence, Rhode Island \\ ${ }^{\mathrm{b}}$ Correspondence regarding this article should be sent to: Christopher Dewey, Providence College Personal \\ Counseling Center, 1 Cunningham Square, Providence, RI 02918 \\ Email: deweyc24@gmail.com \\ ${ }^{\mathrm{c}}$ Note: This article is a reformatted and edited version of my dissertation (Dewey, 2020).
}

\begin{abstract}
The purpose of this study is to explore and discuss the effects of inflexibly enacted traditional masculinity norms (IE-TMNs) on adolescent and young adult males with depression and how to address such issues in therapy. This study provides a literature review of the subject of IE-TMNs and how such a worldview holds a potentially negative influence and impact on the physical and mental health of boys and young men. Specifically, the study aims to highlight how these beliefs, attributes, and values influence the extent to which these individuals seek help, express emotion, and utilize healthy coping skills when experiencing depressive symptoms and how such behaviors can be addressed in therapy. Treatment considerations are explored through the hybrid case example of "Tommy," a depiction of a depressed college freshman following IE-TMNs while going through a difficult life transition. A fictional case, Tommy serves as a composite character informed by real life psychotherapy cases and clinical examples found in relevant literature. Tommy's course of treatment depicts potential clinical issues that could come up when working with a depressed male client with strong internalized masculinity norms and how some of these themes can be adequately addressed to create a more flexible masculine identity. Through use of a qualitative, disciplined inquiry approach, I explore therapeutic interventions that could be utilized to meet the unique needs of such a client within the context of historical, contextual, and cultural factors. Tommy's case material is analyzed qualitatively and quantitatively in accordance with the pragmatic case study research format (Fishman, 2013). The hybrid case of Tommy explores how client-centered therapy, motivational interviewing, harm reduction interventions, and cognitive-behavioral interventions can be integrated to assist adolescent boys and young men with strongly internalized and rigid beliefs about masculinity, while also utilizing Bronfenbrenner's ecological systems theory to explore the proximal and distal factors in one's environment that contribute to such a worldview. The hybrid case study of Tommy is designed to serve as a resource for therapists working with clients with IE-TMNs and provides guidance about how to alter unhelpful coping strategies; increase emotional expression and help-seeking behaviors; and explore personal beliefs, goals, and values. This case study concludes with a critical discussion of future directions for research on this topic, as well as the advantages and limitations of the hybrid case study design.
\end{abstract}

Key words: psychology of men and masculinity; adolescents; young adults; inflexibly enacted masculinity norms (IE-TMNs); depression; alcohol abuse; client-centered therapy; motivational interviewing; harm reduction; ecological systems theory; case study; hybrid case study 


\section{CASE CONTEXT AND METHOD}

\section{The Rationale for Selecting this Particular Client for Study}

Masculinity can be defined as a set of qualities, behaviors, and roles traditionally associated with being a boy or a man. It is both socially-defined and biologically-created, but should be considered distinct from the male biological sex (van den Wijngaard, 1997). Masculine gender socialization is the ways in which gendered social meaning of masculinity come to shape boys' and men's thoughts, feelings, and behaviors (Reigeluth \& Addis, 2010). Traditional masculinity norms in the United States promote stoicism, self-sufficiency, strength, control, aggression, competitiveness, success, fearlessness, and invulnerability (Mahalik et al., 2003). The list goes on to include sexual virility, financial stability, competence, rationality, and independence (Meth \& Pasick, 1990; Pollack, 1998).

In moderation, many of these qualities are desirable and adaptive and may facilitate building relationships, pursuing work, finding success, and attaining happiness. However, when an individual boy or man inflexibly enacts these traditional norms to an extent that is no longer healthy or beneficial at the exclusion of a more dynamic definition of masculinity - that is, when he engages in what I am calling inflexibly enacted traditional masculinity norms (IE-TMNs) this can lead to decreases in physical health, mental health, relationship quality, job performance, and other important areas of daily functioning (Addis \& Mahalik, 2003; Courtenay, 2000).

To a large extent, traditional masculinity norms are socially constructed based on the values, traditions, mores, and taboos of a society at a particular place and time. There have been shifting archetypes of masculinity throughout history - the tough guy, the nerd, the beatnik, the hipster, the jock, the metrosexual, and so on. Depictions of masculinity vary to some degree based on race, ethnicity, socioeconomic status, sexual orientation, and religion, making it a bit shortsighted to view it as a unitary construct (Pollack, 1998). Although there have been multiple social constructions of masculinity over time, the hegemonic, prevailing idea of masculinity as we know it today has managed to pervade mainstream United States society throughout the $20^{\text {th }}$ and early $21^{\text {st }}$ centuries.

Despite the recognition that IE-TMNs contribute to a variety of difficulties in the lives of boys and men, research on how psychologists can address these issues in treatment remains surprisingly limited (Emslie et al., 2006). Specified treatments and assessment measures for working with male clients are relatively few and far between, leaving mental health practitioners in the difficult situation of trying to adapt other treatment strategies to the population (Mahalik et al., 2012). The American Psychological Association (APA) has attempted to mitigate this gap in knowledge through the publication of the APA Guidelines for Psychological Practice with Boys and Men in August 2018 (APA, 2018). These guidelines attempt to address barriers to treatment and outline gender and culture-sensitive psychological practices for working with boys and men from diverse backgrounds. Given that males attend and remain in therapy in far smaller numbers than females, it is imperative that we continue to develop evidence-based treatments that sensitively recognize their unique struggles, make them feel understood and welcomed, and avoid negative and unhelpful stereotypes about masculinity. 
Over the course of my clinical work, I have worked with many depressed male clients who experienced distress due to their strict adherence to masculinity norms or because of the consequences that result from refusing to embody such cultural expectations. Some of these individuals were preteens and adolescents attempting to get a handle on their gender identity and overall sense of self, while others were adults who had attempted to fulfill these norms for a large part of their lives and were no longer able to meet the tiresome demands of upholding IETMNs. In such cases, adherence to these norms was associated with unhealthy relationships, risky behavior, discomfort in expressing emotion, and a reticence to ask others for help. During my interactions with these clients, I attempted to help them formulate an alternative masculinity that would allow them to enact a more flexible gender identity with a healthier set of interpersonal and communication skills, leading to a greater sense of authentic self and increased physical and mental health.

I have used cognitive behavioral therapy (CBT) and Bronfenbrenner's Ecological Systems Theory (1979) as guiding conceptual frameworks to comprehensively explore and understand the idiographic interpersonal, intrapersonal, and community-related factors that influence my clients' adherence to masculinity norms over time. These models consider the combined effects of distal and proximal forces at multiple levels of a client's day-to-day experience and how these forces interact in such a way to shape their values, beliefs, and behaviors. I have used these frameworks to help my clients explore how they first came to hold these beliefs and the reasons why they continue to propagate those values in order to better understand how such worldviews are policed in their lives. Clients are asked to examine how specific relationships, societal attitudes, media messages, and many other factors influence their gender identity and how they enact their beliefs about masculinity on a daily basis. In addition to these models, I found that my male clients also benefited from psychoeducation about the relationship between IE-TMNs and myriad forms of distress in the lives of boys and men.

In line with the above, I have created a hybrid case example, an extension of the pragmatic case study, to explore the ways in which IE-TMNs are associated with fewer health promotion behaviors, more pronounced mental health struggles, and lower quality relationships for adolescent boys and young adult men. Specifically, I am interested in highlighting how inflexible adherence to these norms is related to experiences with depression. This fictional hybridized case combines interactions and themes that I have encountered throughout the course of treatment with my clients with findings and encounters detailed in the relevant literature in order to elucidate the ways in which IE-TMNs are connected to depressive symptoms. By using this fictional character, I explore the systemic ways in which masculinity norms are propagated, internalized, and policed and describe how therapists can discuss these themes in treatment and assist their male clients in developing a more flexible sense of masculinity.

This hybrid case study will realistically depict common presenting problems and key clinical issues that arise when working with adolescent and young adult males who are facing difficulties due to IE-TMNs and how this process impacts experiences with depression. This case highlights common psychotherapy experiences and an ideal course of treatment. It will also focus on the need for preventative measures that educate boys and young men about traditional masculinity beliefs before the norms are overly ingrained as IE-TMNs. 
Although it is important for this case to be comprehensive in how it captures important themes, it will not represent the experiences of all boys and men due to the fact that masculinity norms and the extent to which they are socially enforced often differ by race, ethnicity, culture, sexual orientation, generation, and other important identity factors. In light of the dearth of research on this topic, it is crucial that more attention be given to such concerns in order to explore and understand the best clinical practices for addressing such themes in treatment and to identify preventative measures that deter the internalization of inflexible beliefs about one's masculinity at a young age before they become ingrained. Ultimately, this example will underscore a need to increase the mental health field's understanding of how to discuss these issues with adolescents and young men, facilitate more beneficial treatment outcomes, and develop preventative measures that address these beliefs and values at an early age.

The structure of this project will follow the format of a pragmatic case study as described by Fishman (2013). As such, it will include a detailed description of the hybridized client and the setting in which treatment took place; assessment of the hybridized client's presenting problems, goals, strengths, and history; a literature review on research relevant to the case; the theoretical guiding conception; case formulation and treatment plan; course of treatment; therapy monitoring and use of feedback; a final quantitative and qualitative analysis of treatment outcomes; and a discussion of limitations of this study and areas for future research. Through taking a qualitative, disciplined inquiry approach, I will be able to describe a course of treatment that addresses the hybridized client's struggles with depression and the influences of masculinity norms on his experiences, while considering cultural, historical, and contextual factors that are relevant to his life.

Fictionalized scores on quantitative measures are also employed in an attempt to illustrate the hybridized client's struggles with their masculinity over time and observe how his depressive symptoms parallel these concerns. Through use of these measures, I seek to illustrate how therapists can reassess their intervention strategies over the course of treatment in order to identify what works and what does not work when it comes to meeting their clients' needs and reducing their distress. Although this quantitative data is fictionalized, it is representative of trends that I have observed when working with adolescent and young adult males struggling with IE-TMNs and symptoms of depression.

The hybridized case depicted in this case study is a composite of male clients between the ages of 14 and 22 that I have provided with short and long-term treatment during my four years as a doctoral-level graduate student. These cases were seen in a middle-school/high-school counseling center, a college counseling center, and a partial hospitalization/intensive outpatient program. While I have also worked with male clients who were both older and younger than this specified age range, I have chosen to focus on adolescent and young adult clients, as the identity formation that takes place during those years is often where the internalization of gender norms is intensified. As such, this age group serves as a particularly critical entry point for psychologists to help boys and young men explore beliefs about masculinity and attempt to prevent harmful outcomes in the future that may result through the development of IE-TMNs. The hybrid case in this study will focus on a client attempting to grapple with masculinity-related struggles for the first time in his life as he adjusts to college and seeks to navigate the transition 
between adolescence and young adulthood and the independence and responsibilities that come with it.

The hybridized clinical case in this study, hereafter referred to as "Tommy," is an 18year-old college freshman attending mandated treatment at his college counseling center after multiple alcohol-related infractions. He presents with symptoms of depression and alcohol use disorder. Tommy does not recognize his symptoms as being overly problematic and, instead, believes that he is behaving in a normative manner for a male college freshman. Although he is not a stereotypical hypermasculine individual at first glance, Tommy has unknowingly internalized many of the mainstream messages about what it means to be a man in the United States.

\section{The Clinical Setting in Which the Case Took Place}

Tommy attended treatment at a university counseling center in a suburban town in the Northeastern United States. He was not required to provide payment for sessions, as this cost was already covered by administrative and campus fees he paid each semester. Tommy attended 16 therapy sessions in the spring semester of his freshman year of college. During this time, the counseling center attempted to limit students to one semester's worth of treatment but was flexible in some cases. Tommy understood that I had a one year placement at the counseling center, and he would need to meet with another clinician if he desired services beyond May. Throughout treatment, I received individual supervision from a licensed professional psychologist who utilized cognitive-behavioral therapy in her own practice. I also took part in group peer supervision with the other trainees in the counseling center. Supervision topics included depression, substance abuse, masculinity norms, motivational interviewing, and harm reduction.

\section{Sources of Data Available Concerning the Client}

Before the start of treatment, I had access to a brief 10-minute phone intake that an administrative assistant had conducted with Tommy. Additionally, Tommy completed the Outcome Questionnaire-45 (OQ-45; Lambert et al., 2004) and the Patient Health Questionnaire9 (PHQ-9; Kroenke et al., 2001) prior to the start of his intake, which were both given to me to review before meeting with him. The OQ-45 measures symptom distress, interpersonal relations, and social role performance. The PHQ-9 is a nine-item inventory used for screening, diagnosing, monitoring, and measuring severity of depression. More about the OQ-45 and the PHQ-9 is presented below in the Assessment section. Otherwise, Tommy had not attended treatment in the past, so there was no prior clinical information to obtain. Collateral information was provided by the university's residence life staff.

\section{Confidentiality}

The hybridized client, Tommy, is not a real person. Instead, he is composite character that combines aspects of multiple cases I have worked on, as well as notable examples found in the relevant literature. Combining clinical examples, changing identifiable details, and adding 
fictional elements will allow me to explore key themes that might not necessarily be encompassed in a single case study, while also maintaining real life client confidentiality.

\section{THE CLIENT}

"Tommy" was an 18-year-old Caucasian, heterosexual male college freshman who was mandated by his university's residence life staff to attend counseling after three alcohol violations in his first semester of college. His treatment was comprised of sixteen individual 50minute sessions over the course of five months. During his intake, Tommy was guarded, uncomfortable, and terse, though he was also polite and respectful to all of the counseling center staff. Despite his initial resistance to engage in treatment, Tommy stated that he wanted to address his anger, "moodiness," alcohol use, and relationship struggles while in treatment. However, he indicated that he was skeptical about the effectiveness of therapy and was hesitant to take ownership of his distress, instead, suggesting that others around him were largely responsible for his difficulties and low mood. Tommy reported that he had never attended therapy before but felt that he knew what it would be like based on what he had seen on television and in movies.

Tommy presented with symptoms of Major Depressive Disorder, Single Episode, Moderate, as defined by the American Psychiatric Association's (2013) Diagnostic and Statistical Manual of Mental Disorders, Fifth Edition (DSM-5). His symptoms included a depressed mood, anhedonia, increased appetite, weight gain, hypersomnia, fatigue, concentration difficulties, and feelings of worthlessness. Tommy also presented with considerable anger and irritability. He denied having thoughts of death or suicidal ideation. Tommy also met the DSM-5 criteria for Alcohol Use Disorder, Moderate. He indicated that he had been experiencing a problematic pattern of alcohol use defined by drinking larger amounts of alcohol over a longer period than intended, drinking alcohol in a way that prevented him from fulfilling major role obligations at school and home, continued alcohol use despite recurrent interpersonal problems caused and exacerbated by drinking, and recurrent alcohol use in situations where it was potentially physically hazardous.

\section{GUIDING CONCEPTION WITH RESEARCH AND CLINICAL EXPERIENCE SUPPORT}

\section{Masculinity Norms and the Development of IE-TMNs}

Traditional masculinity norms are engrained in males starting at a young age. These attitudes, beliefs, and values are typically endorsed, intensified, rigidly guarded, and propagated through interpersonal relationships and interactions (Liu et al., 2005). From birth, boys are taught which behaviors, emotions, attitudes, colors, toys, and activities are socially appropriate and acceptable for their gender (Pollack 1998; Pollack, 2006). As they grow older, they are taught that they must disengage from their mothers and avoid behavior that could be construed as feminine, "gay," or overly reliant. Boys and teenagers who are seen as too attached to their mothers are viewed by many as weak, feminine, vulnerable, and excessively emotional. They may be disparaged by others around them as "momma's boys" and "girly men." The pressure to distance oneself from supportive caregivers and the shame that can come from failing to do so 
impacts an individual's ability to form secure attachments later in life, as they feel pressure to avoid the self-disclosure, vulnerability, and help-seeking behaviors that contribute to strong, intimate relationships (Pollack, 1998; Pollack, 2006). In turn, they learn that they must handle their problems on their own and hide unacceptable displays of pain.

Young boys are especially influenced by the implicit and explicit expectations and assumptions about masculinity that are conveyed to them by peers, parents, teachers, and other important caregivers with whom they interact on a frequent basis (Mahalik et al., 2003). Through direct interactions and social observations, young males learn and internalize what it means to be a man in mainstream United States society, leading them to either extend the legacy of traditional masculinity norms or attempt to break away from the prevailing ideology and risk social ostracism and shame ( $\mathrm{Li}$ et al., 2006). Considerable distress may result from extensive steps taken to uphold these norms and mask how one truly feels at all times (Reidy et al., 2018). To many boys and men, such efforts are considered worthwhile when they observe how their less conforming peers are ridiculed and stigmatized for constructing alternative masculinities.

Distal forces like the mass media compound the messages, expectations, and assumptions put forth about masculinity by familiar others. From childhood, males are exposed to images in movies, television, and popular print media that detail what it means to be a man (APA, 2018). Characters like the hard-drinking, womanizing spy James Bond or tough, fearless, dutiful superheroes like Batman provide male audiences with unrealistic, unhealthy, and unsafe expectations about how they are expected to behave as members of their gender (Craig, 1992; Ward et al., 2006). Throughout many of these depictions of men, reckless substance use is portrayed as harmless and manly, violence and other forms of aggression are depicted as the best method to solve problems, and a man's sexual prowess comes to be seen as an indication of his self-worth. The relative lack of diversity in how men are portrayed in the mass media is at least partially responsible for why so many boys and men feel the need to exercise such a restricted definition of masculinity.

As powerful as the mass media may be, the rise and pervasiveness of social media platforms has proven to be even more influential in spreading, reinforcing, and popularizing traditional masculinity norms. These websites and phone applications are a major force in identity development, especially for adolescents (de Vries et al., 2016). Such platforms have the ability to provide guidance about what is considered masculine and feminine and often succeed in propagating socially acceptable gender-role behavior as determined by mainstream United States society (de Vries et al., 2014). Unlike the fantastical depictions of men in movies and television, young users of social media are more likely to believe that the images of their masculine peers on social media are realistic and easier to replicate (Rutledge et al., 2013). These children and adolescents fail to recognize that they are viewing meticulously selected and edited images and may miss the artificial nature of social media in the process of making social comparisons. One study found that traditionally male pictures on Facebook emphasized the user's social status and strength through photographs that stressed their clothing, muscularity, pose/stance, and cars (Tifferet \& Vilnai-Yavetz, 2014). Common pictures depicted male subjects looking indifferent, stoic, and tough, rather than happy and enthusiastic. 
Boys and men who frequently view these types of pictures on social media platforms may internalize traditional, inflexible views of masculinity and attempt to bulk up their physique by engaging in various exercise behaviors and eating in such a way that will lead to increased muscle mass (Kim \& Chock, 2015). While increased levels of exercise may be quite important for some males, it may result in boys and men over-exerting themselves to attain an unrealistic and, in many cases, unhealthy body type. One study found a positive correlation between the amount of time that male users spent on social networking sites and increased body dissatisfaction (de Vries et al., 2016). Additionally, increased social media use was also found to predict an increased peer influence on body image and an increased need to receive appearancerelated feedback from peers. It is clear that these platforms are particularly influential in shaping and spreading masculinity norms.

\section{Impact on Health}

There is evidence that inflexibly enacted traditional masculinity norms (IE-TMNs) negatively impact the health behaviors of boys and men. Higher endorsement of hegemonic norms is associated with a greater number of health risk behaviors (e.g., unhealthy diet, not wearing a seat belt, and drinking and driving) and fewer health promotion behaviors (e.g., exercising, attending regular medical and dental appointments, and eating a balanced diet) (Mahalik et al., 2007). One study found that, among a group of 140 men between the ages of 1878 , adherence to hegemonic norms and perceived normativeness of other traditional men's health behaviors predicted one's own health behaviors (Mahalik et al., 2007). This finding held true across various socio-demographic factors. Endorsement of these values was also found to be associated with an increase in specific medical concerns, including reduced sleep and higher rates of heart disease, physical injury, disability, poorer diet, increased smoking and alcohol use, and premature death (Addis \& Mahalik, 2003; Courtenay, 2000; Meth \& Pasick, 1990). Boys and men who exhibit IE-TMNs and happen to be disabled or face chronic illness may feel a sense of emasculation over their inability to take care of themselves and provide for others (Seidler et al., 2016). The need to rely on others, many of whom might be female, and the inability to manage problems on their own might instill a unique sense of shame in these individuals.

In additional to physical health, mental health also appears to be negatively impacted by IE-TMNs. Adherence to these norms has the potential to contribute to and compound distress (Mahalik et al., 2003). At the same time, failure to adhere to masculinity norms can also result in distress because of ridicule and ostracism from others who see value in such qualities. Such stress has been found to predict increased anger, anxiety, and depression, and poorer overall mental health-related quality of life (Eisler et al., 1988; Mahalik et al., 2003). Boys and men who strongly subscribe to traditional masculinity norms also report increased rates of emotional restriction and interpersonal conflict and isolation, as well as lower self-reports on measures of self-esteem (Mahalik et al., 2015). Strong adherence to these values also alters how males exhibit symptoms of psychopathology, leading many to believe that it is non-masculine to outwardly exhibit vulnerability or describe their pain to others (Reigeluth \& Addis, 2010). For many boys and men, the mere idea of being viewed as vulnerable is liable to make them feel even more anxious. In turn, it is all too common for boys and men who rigidly uphold these traditional 
masculinity standards to shut down when they are upset or externalize their symptoms in a manner that is considered more socially acceptable for males (Seilder et al., 2016).

The negative physical and mental health effects that result from enacting an overly rigid and traditional worldview of masculinity are exacerbated by the fact that boys and men who uphold these values are often reluctant to seek help when they are struggling or in pain (Reigeluth \& Addis, 2010). For these individuals, it may be difficult to relinquish control and place themselves in the care of an experienced, knowledgeable professional. There is a strong negative correlation between IE-TMNs and help-seeking behaviors, making males with such values less likely to go to the doctor or speak with a mental health professional when they find themselves in distress (Mahalik et al., 2003; Meth \& Pasick, 1990). They may deny illness, hide negative emotions connected to their pain, and exhaust internal psychological and physical resources to avoid admitting that they are struggling (Seidler et al., 2016). When it comes to dealing with mental health concerns, males with traditional beliefs about masculinity appear to have a pronounced preoccupation about therapy and are half as likely as females to seek services (Reigeluth \& Addis, 2010). This finding is consistent across geographic location, racial and ethnic groups, and age groups. These boys and men are often fearful of the stigma and coercion that they believe accompanies therapy and, in effect, exhibit lower rates of attendance and engagement, as well as more difficulty fostering stable therapeutic alliances. Due to lower attendance, many mental health professionals erroneously conclude that males have fewer mental health-related difficulties in comparison to females, when in fact psychologists and other mental health experts may be failing to properly account for them because of their absence from therapeutic settings or other contexts in which they could be accurately diagnosed (Emslie et al., 2006; Martin et al., 2013).

\section{Masculinity Norms and Depression}

A growing, though incomplete, body of research details how boys' and men's IE-TMNs can impact and contribute to the manifestation of depression and ensuing experiences of trying to manage the functionally impairing and distressing symptoms of the disorder. Depression is believed to negatively impact at least 350 million people worldwide, making it the leading cause of disability (WHO, 2016). It has the potential to impair one's ability to experience happiness and fulfillment, foster meaningful relationships, maintain employment, support a family, and engage in other important day-to-day tasks. At least six million men suffer from depression in the United States, and it is estimated that roughly 20-35\% of adolescent males exhibit high levels of depressed mood (Hankin, 2006; NIMH, 2003). Although depression rates in males are about half of those found in females starting in adolescence, males complete suicide anywhere between four to 15 times more often than females (Mahalik \& Rochlen, 2016). Along with suicide, males exhibit far higher rates of substance use and physical violence in comparison to females when they are depressed (Seidler et al., 2016). Despite the widespread belief that males are less likely to experience depression, some believe that there is evidence to suggest that available prevalence rates are misleadingly low and obscure the true level of impact of the disorder for boys and men (Emslie et al., 2006; Pollack 1998).

There are many explanations for why rates of depression are higher in adolescent girls compared to boys. Some have suggested that boys and men may present with a "hidden" 
C. Dewey

Pragmatic Case Studies in Psychotherapy, http://pcsp.libraries.rutgers.edu

Volume 16, Module 3, Article 1, pp. 237-304, 12-28-20 [copyright by author]

depression that is masked by substance use and other externalizing problems (Addis, 2008). Others have suggested that males may even not be depressed less than females and that mental health professionals may just be failing to properly diagnose males because of how they express their distress (Seidler, 2016). Pollack (1998) argues that the number of depressed males in the United States appears to decrease during adolescence because traditional masculinity norms and associated ideologies steer them away from outwardly expressing signs of weakness or seeking help to manage their distress. Instead of conveying sadness or worry, many males feel more comfortable expressing their depression through anger, irritability, risky behaviors, psychosomatic complaints, and other externalizing means, all of which escape the traditional criteria for depression (Reigeluth \& Addis, 2010). It has also been observed that earlier onset of puberty for girls might be partially responsible for the increase in female depression prevalence compared to that of boys (Hankin, 2006). The struggles of managing this developmental change are compounded by the fact that the girls are more likely than boys to experience a higher number of stressors, especially interpersonal stressors, during adolescence (Hankin et al., 2007).

Psychologists and other mental health professionals must develop better screening methods to identify boys and men with depression that are not detected by traditional means. Additionally, they should seek to develop new assessment tools and clinical interventions that allow them to more effectively work with boys and men who are adversely impacted by IETMNs and increase their utilization of and commitment towards mental health services (Seidler et al., 2016). Since it may be difficult to tell if a male client's symptoms are a result of IE-TMNs, it is best practice to always consider how one's perception of gender could be impacting their presentation and consider its role in relation to their values, personality traits, symptoms, and environmental contexts (Reigeluth \& Addis, 2010). Furthermore, therapists should question how high risk behaviors, such as fighting, gambling, and excessive substance use are related to internalized masculinity norms and explore how social-environmental cues make such behaviors more or less likely. Therapists may also want to question how the socially-constructed masculinities that impact their male clients' manifestations of depression are related to social power dynamics and hegemonies that favor males over females and promote strength at the expensive of vulnerability, warmth, and caregiving (APA, 2018).

There is some evidence to suggest that boys and men with less favorable appraisals of therapy might be more receptive to a treatment that is collaborative, short-term, and group-based, though it is unclear at this time if such a modality is necessarily efficacious for that group (Seidler et al., 2016). Additionally, although many of these male clients are likely to discuss masculinity in a stereotypical manner, it is crucial for therapists to portray masculinity as a multifaceted, fluid concept rather than a unitary construct. Working from a purely deficit-based model that spends too much time dwelling on the unhelpful aspects of traditional masculinity norms is unlikely to lead to change and, instead, often succeeds in threatening the client and inadvertently pushing them away from treatment (APA, 2018).

Instead, when working with depressed boys and men, it may prove more productive for therapists to start by working with the client to explore the positive aspects of their masculinity (e.g. courage and determination) before they place excessive focus on trying to reverse IETMNs. The therapist can help the client explore what they believe it means to "be a man" and why they feel it is so important to enact these norms so rigidly (Reigeluth \& Addis, 2010). It is 
also important to learn where these messages came from and if they ever faced any negative consequences or punishment because they strayed from socially acceptable masculinity scripts (Pollack, 1998). The therapist can assist the client in exploring whether their embodiment of masculinity norms varies and shifts based on environmental context and why it may be easier to be more flexible with these norms in some situations versus others.

\section{Therapy Models Employed}

Throughout my work with Tommy, I utilized interventions from a number of different theoretical orientations to address his presenting concerns. These theoretical orientations included cognitive-behavioral therapy, motivational interviewing and harm reduction techniques aimed at reducing harmful substance use, and client-centered therapy. I also made use of Bronfenbrenner's Ecological Systems Theory in order to explore the social forces in Tommy's life that were influencing his beliefs about masculinity in order to have a clearer case conceptualization. The psychological literature suggests that these treatments are effective when working with clients who present with depression, anxiety, and substance use, which are all common co-occurring issues for clients who strictly adhere to traditional masculinity norms (Mahalik et al., 2012). To date, there has been limited research dedicated towards developing evidence-based treatments that specifically target men and struggles with masculinity beliefs (APA, 2018). Additionally, there are even fewer treatments designed for treating adolescent males who also struggle with similar identity concerns. As such, my interventions were largely selected based on their efficacy in treating depressive symptoms and alcohol use, two of Tommy's major presenting concerns.

\section{$\underline{\text { Cognitive-Behavioral Therapy }}$}

Cognitive-behavioral therapy has been found to be a preferred treatment modality for many adult men because of its short-term nature, utilization of practical problem-solving strategies instead of "just talking," and emphasis on a collaborative partnership (Seidler et al., 2016). For the purposes of my work with Tommy, I did not utilize a specific CBT manual that focused on masculinity issues. Instead, I drew from evidence-based behavioral and cognitive techniques that have been found to be effective in alleviating depressive symptoms and minimizing dangerous alcohol use. I utilized behavioral activation to help Tommy gain a greater awareness of how different daily activities impacted his mood and set the stage for increasing rewarding pursuits and interpersonal interactions, while minimizing vegetative and/or harmful behaviors that were perpetuating his symptoms (Persons, 2008). Similarly, I also made use of cognitive restructuring to allow Tommy to analyze his automatic thoughts, identify intermediate beliefs, and explore his core beliefs about himself, others, and the world (Beck, 2011). I believed that exploring these beliefs would also assist him in reflecting on his personal values and goals and allow him to construct a healthier masculine identity for himself.

\section{Motivational Interviewing}

Both motivational interviewing and harm reduction have been identified as effective, evidence-based treatment options for helping clients take ownership of their substance use, reduce the frequency and quantity of their use, and minimize the negative effects that stem from 
their use (Neighbors et al., 2006; Persons, 2008). Given that Tommy was experiencing negative outcomes stemming from alcohol use but did not appear to be physically dependent, I decided that it would be mode prudent to emphasize healthier and more cautious consumption of alcohol rather than aim for total abstinence. This decision was partially driven by the realization that we only had a semester-long window to work within and the fact that it was necessary to also simultaneously attend to his depression and IE-TMNs during that timeframe.

\section{Client-Centered Therapy}

Additionally, as I would in any treatment, I drew on the common factor core principles of client-centered therapy in order to build a strong therapeutic alliance with Tommy based on trust and understanding and properly acclimate him to treatment. Client-centered therapy emphasizes genuineness, unconditional positive regard, and empathy (Rogers, 1961). Genuineness refers to the therapist's willingness to openly relate to the client and share honest, candid reactions to what they are saying. Similarly, unconditional positive regard emphasizes the therapist's commitment to holding a positive and accepting attitude towards their client regardless of what they are going through at that moment in order to facilitate a learning environment in which the client can openly express feelings without fear of rejection. Lastly, the therapist shows the client empathy by reflecting their thoughts and feelings and allowing them to feel validated and understood. My hope was that these qualities would make Tommy feel comfortable in therapy and give him space to safely discuss his experiences and explore identity issues without fear of judgment or coercion. Based on the empirical research literature documenting the efficacy of particular procedures in addition to common factors (Persons, 2008), I did not expect that clientcentered principles alone would allow me to sufficiently address all of Tommy's presenting concerns. However, based on the empirical research literature documenting the importance of client-centered principles in contributing to positive therapy outcomes (Norcross et al., 2019), I believe that my later interventions would have been far less successful without the foundational elements of client-centered therapy.

\section{Ecological Systems Theory}

I employed Bronfenbrenner's Ecological Systems Theory as a conceptualization tool to explore and understand where Tommy's beliefs about masculinity began and how they had been internalized and reinforced over time. Ecological Systems Theory examines how an individual's microsystem (e.g., family and peers), mesosystem (e.g., interactions between different components of the microsystem), exosystem (e.g., mass media, social media, and community resources), and macrosystem (e.g., cultural attitudes, values, and mores) interact to impact one's lived experience (Bronfenbrenner, 1979). I did not explicitly discuss this theory during my conversations with Tommy and, instead, utilized it to shape my case formulation and guide the structure of my conversations about IE-TMNs with him. I believed that Tommy would benefit from a better understanding of how he came to hold certain beliefs over the course of his development and how such an ideology can be maintained over time. 


\section{$\underline{\text { Synthesis and Phases }}$}

Overall, I synthesized the-above described theoretical orientations to construct an idiographic treatment plan that addressed all of Tommy's presenting concerns. Specifically, I broke treatment down into five distinct phases, assigning specific goals and interventions to each phase. Phase 1 was largely focused on orienting Tommy to treatment and building rapport through client-centered therapy principles and techniques as a foundation for therapy.

Phase 2 was dedicated towards reducing harmful alcohol consumption through use of motivational interviewing and harm reduction strategies. I viewed Tommy's substance use as a potential treatment obstacle and believed that it would need to be adequately addressed before we could begin meaningful work on his depressive symptoms or IE-TMNs.

Phase 3 aimed to alleviate Tommy's depressive symptoms, first through behavioral activation and then cognitive restructuring.

During Phase 4, I continued to employ both behavioral and cognitive techniques, this time specifically focused on beliefs and behaviors that stemmed from Tommy's internalized masculinity norms. Throughout this phase, I also wanted Tommy to become more aware of the messages that he received from family, friends, and society about masculinity and begin to construct his own idea of what he wanted his masculinity to entail.

Finally, in Phase 5 I aimed to assist Tommy in consolidating treatment gains, reviewing coping skills, and appropriately terminating treatment in order to maintain the strong therapeutic alliance that we had 'built over the course of the semester.

\section{ASSESSMENT OF CLIENT'S PRESENTING PROBLEMS, GOALS, STRENGTHS, AND HISTORY PRESENTING PROBLEMS}

Tommy was mandated to attend treatment in the counseling center by the residence life staff of his university after he incurred three alcohol-related violations during the fall semester. He was originally written up by his RA in September after he and his friends were caught loudly playing drinking games in his room. Tommy's second alcohol violation took place on Halloween after he drank excessively, blacked out, and passed out alone in his room. His friends were concerned about his well-being and could not reach his roommate. As such, they contacted the RA on the floor to open the door and check up on him. Upon opening the door, his RA discovered that he had been vomiting profusely and had him sent to the campus infirmary overnight. The third alcohol incident took place in December days before Tommy was to head home for winter break. To celebrate the end of finals, Tommy and his friends engaged in an evening of heavy drinking. When one of his female friends decided to head back to her dorm for the night, Tommy pursued her in the hopes of "hooking up" with her. The two of them had been romantic on one other occasion but she had since made it clear to Tommy that she had rekindled a relationship with her boyfriend and was not interested in him. Tommy argued with this woman all the way back to her dorm, at which point she went into her room, locking him out. Tommy continued to try to persuade her through the door and continuously knocked when she stopped responding to him. At some point, this woman called campus security and Tommy was escorted 
to the infirmary again. After these three incidents, he was informed that he would have to partake in counseling if he wanted to remain at the university for the following semester.

Tommy reported that he first began drinking in the spring of his senior year of high school when he started going to a lot of parties. Before that, he indicated that he abstained from all substances because he played basketball and baseball and was concerned that he would be kicked off of his teams if he got in trouble. Tommy denied any current or past use of illegal drugs or nicotine. Throughout the fall semester, he reported that he consumed 8-12 alcoholic beverages most Fridays and Saturdays. Towards the end of the semester, Tommy stated that he began drinking 2-3 beers on three nights out of the school week to deal with stress and frustration. While his weekend binge drinking was typically social in nature, his weekday drinking was solitary. Tommy reported that he had not had any alcohol since returning to campus for the spring semester out of fear of getting caught again. He stated that he was frustrated that he had to abstain because "most of [his] friends drink more than [him] anyway and never face any consequences." Tommy disliked being the only sober one on the weekends and had started to stay in his room and watch movies alone rather than go out with his friends.

During his intake, Tommy completed paperwork and self-report measures in which he endorsed a number of depressive symptoms. He was surprised when I questioned whether or not he felt depressed, stating, "That's not a word I would've ever used to describe myself." Tommy reported that he did not believe he had ever experienced depression before but noted that both his mother and maternal grandmother had experienced varying levels of depression throughout their respective lives.

Tommy stated that his mood and drinking had both worsened in October when he discovered that his girlfriend of three years, Ashley, had cheated on him at college and then subsequently dumped him. Commenting on the breakup, he said, "I wasn't all sad and weepy after that. Just pissed off and irritable most of the time. I think that was sort of an understandable response given what had happened to me."

Since then, he had started to withdraw from most social activities during the week and reported that he spent most of his time watching television, "messing around on his laptop," and sleeping. He indicated that he would spend a lot of time monitoring his ex-girlfriend's social media accounts to see if she had a new boyfriend, while also scrolling through the profiles of other female peers to plot out his next relationship or "hookup" in order to make himself feel better. Tommy admitted that he had missed a number of morning classes during the fall semester but was able to get away with it because they were large lecture hall classes that did not take attendance. Nevertheless, he stated that it quickly became hard for him to stay on top of assignments and that he usually turned papers in late when he could not get an extension. Traditionally a straight "A" student, he ended the semester with three "Cs" and two "Bs." Even though he kept to himself when he drank during the week in the fall, Tommy reported that he would still hang out with his friends when they were drinking on the weekends because it allowed him to "blow off some steam and let loose." However, he believed that many of his friends were growing both aggravated and concerned about his erratic drinking behavior, as well as his seclusion during the week, and were not reaching out to him to hang out as much as before. 
Although Tommy expressed annoyance that he had to attend treatment, he stated that it was important for him to make some necessary changes so that he could stay in school. Tommy acknowledged that he had an "off" semester and recognized that his grades and social life would only continue to deteriorate if he did not "get his shit together." Despite his belief that he was not drinking more than his peers, he possessed enough insight to understand that alcohol had become a negative force in his life. Tommy reported that he thought he could make needed changes on his own and did not believe that therapy was necessary to facilitate a shift in his life but said, "I might as well give this thing a try if I absolutely have to be here."

\section{Quantitative Assessment}

Throughout treatment, Tommy completed three psychometrically sound qualitative measures every third session. Tommy filled out these measures before the start of our sessions in order to maximize our time together. It was important for me to have him complete these forms so that I could monitor his distress level, symptom intensity, and overall treatment progress and make changes in the treatment plan if necessary. I had him complete the measures every three sessions partially because the counseling center suggested such a schedule but also because I did not want to burden him with arriving early every session and completing tedious paperwork all of the time. I used Tommy's initial scores to determine his level of functioning at the start of treatment. As he continued to complete the forms, we discussed his responses during sessions and I asked him if he thought his scores accurately mirrored his lived experience.

The counseling center required that all clients complete the Outcome Questionnaire-45 (OQ-45) at the time of their intake and then every three sessions afterward. The OQ-45 is a $45-$ item self-report measure designed for repeated administration to measure a client's level of functioning throughout therapy (Lambert et al., 2004). The measure asks respondents to rank different areas of functioning on a 5-point Likert scale. The OQ-45 provides subscale scores in the areas of Symptom Distress, Interpersonal Relations, and Social Role. The measure also includes five critical items that help a clinician screen for suicidal ideation, substance abuse, and anger and violence at school or in the workplace. The OQ-45 provides a broad overview of a client's distress and should not be used as a diagnostic measure. Tommy's OQ-45 results are provided in Table 1. At his intake, Tommy's OQ-45 total score was above the clinical cut-off, as were his three subscale scores, suggesting that he was experiencing considerable distress across multiple life domains.

Additionally, since Tommy was experiencing depressive symptoms, he was administered the Patient Health Questionnaire-9 (PHQ-9) every third session beginning at intake. The PHQ-9 is a 9-item self-report measure (items scored 0-3) that assesses depressive symptoms and depression severity according to DSM criteria (Kroenke et al., 2001). A total score of 0-4 indicates none to minimal depression; 5-9 mild depression; 10-14 moderate depression; 15-19 moderately severe depression; and 20-27 severe depression. The PHQ-9 serves as a screening measure, diagnostic tool, and symptom tracking method, allowing a clinician to observe symptoms over time and alter treatment strategies as needed to ensure optimal progress. Tommy received a score of 16 at the start of treatment, suggesting that he was experiencing moderately severe depression. Tommy's PHQ-9 scores are provided in Table 2. 
Tommy also completed the Meanings of Adolescent Masculinity Scale (MAMS; Oransky $\&$ Fisher, 2009) at the start of his fourth session and then every third session throughout treatment because it was hypothesized that his depressive symptoms and level of distress were at least partially attributable to rigid adherence to traditional masculinity norms. The MAMS is a 27-item, self-report measure. Items were generated from interview data and through focus group discussions with adolescent boys. The authors of the measure describe its development as follows. "The resulting questionnaire, along with convergent validity scales, was completed by a diverse group of $1937^{\text {th }}$ through $10^{\text {th }}$-grade boys. Factor analysis supported a 4-factor model: Constant Effort, Emotional Restriction, Heterosexism, and Social Teasing. Subscales derived from this analysis yielded good internal reliability. Convergent validity was supported by significant correlations between MAMS subscales and existing measures of male role norms and psychological adjustment" (Oransky \& Fisher, 2009, p. 57). Each of the 27 items is responded by the participant answering "1 - strongly disagree," "2 - disagree," "3 - agree," or "4 - strongly agree." Sample items from the subscales are as follows:

*** Constant Effort

"A guy should always seem as manly as other guys that he knows."

"A guy must appear confident even if he isn't."

"Getting made fun of helps guys become tough."

*** Emotional Restriction

"It is weird for a guy to talk about his feelings with other guys."

"When a guy has a fear, he should keep it to himself."

"It is hard to respect a guy who shows his feelings."

*** Heterosexism

"Being thought of as gay makes a guy seem like less of a man."

"There is something wrong if a guy wants to do activities usually done by girls."

"Real guys never act like a girl."

*** Social Teasing

"A guy should be able to take teasing from his friends."

"It is normal for guys to make fun of their friends."

"In order to fit in, guys must be able to tease other guys."

A copy of the full scale is presented in Table 3.

To date, there is no information published regarding what constitutes a high, moderate, or low score on the total score or four subscale scores of the MAMS. Due to this lack of information, the MAMS was only utilized as a relative gauge of Tommy's traditional masculinity beliefs over the course of therapy. Tommy's MAMS scores are provided in Table 4.

\section{Relevant Personal History}

Tommy grew up living with his mother and maternal grandparents in a suburban town in the northeastern United States. His parents divorced when he was 4-years-old, and his father relocated to Ohio. Tommy described a warm relationship with his mother and stated that they have been close his entire life, though he mentioned that they started spending less time together 
as he entered his teenage years. He stated that his mother was an encouraging and validating individual who was always accepting of his emotions, describing her as "a sort of home base for me when I needed to let my guard down." Tommy reported positive relationships with his grandparents as well. He stated that his grandmother was nurturing and warm, making her a formidable foil to his grandfather, a retired police officer who was "rough and tumble." Tommy indicated that his grandfather was supportive when it came to school, sports, and his general well-being but had specific ideas about how a boy should behave and could be dismissive when he felt Tommy strayed from this script. Overall, Tommy described his home life as mostly positive, as long as he kept a low profile when his grandfather was in a bad mood or drank too much. He noted that he did not ever think of his grandfather as an alcoholic but recognized that he did drink most nights of the week and was often difficult to interact with during those occasions in which he drank heavily.

Growing up, Tommy only saw his father once or twice a year and maintained irregular phone contact with him. Tommy reported that he often grew anxious as a reunion with his father approached because he had a tendency to be critical of him and was liable to mock him when he failed to succeed at tasks or struggled during games. Like his grandfather, Tommy stated that his father was prone to heavy alcohol use and could be quiet derisive and cruel when he drank. He suspected that his parents' failed marriage and his father's inability to maintain a steady job were both at least somewhat attributable to his father's alcohol use. Although Tommy later came to understand that his father was in considerable emotional pain due to failures in own his life, any opportunity to witness such vulnerability was usually masked by his father's anger and irritability. Tommy stated that he tried to be a "hardened blank slate" when he was with his father because it made him feel strong and gave his father fewer opportunities to insult him.

Tommy excelled at most ventures in his life prior to college. In high school, he maintained an "A" average and consistently made the honor roll. He was recognized as an exceptional athlete and played on his high school's varsity basketball and baseball teams. Although he reported that he never considered himself one of the most popular people in school, he recalled that he was generally well-liked by people from most social circles. Tommy maintained a core friend group of five male classmates that he had known since elementary school. He described their relationships as activity-based, stating that they spent their time playing sports and video games, going to the movies, attending parties, and riding their bikes (and later driving) around town to meet up with girls. While they had each other's backs and were loyal to one another, Tommy indicated that they "liked to give each other shit" and make fun of each other. He commented, "If someone was whining or seemed upset we'd sometimes make fun of them or tell them to 'stop acting gay.' That probably sounds homophobic to you but I don't think we ever really meant it to be like that. I'd like to think that if one of us turned out to be gay we'd be cool about it."

Tommy began dating his now ex-girlfriend, Ashley, during their sophomore year of high school. They were each other's first romantic relationships and were nearly inseparable for the three years leading up to college. During the summer between their sophomore and junior years, the two of them lost their virginities to each other and started talking about having a long-term future together. Tommy reported that Ashley was a particularly important figure in his life because she allowed him to open up and be vulnerable, something that he felt he could not do 
around his male friends without getting teased. He indicated that he chose to go to his particular university because it was only an hour away from Ashley's and would make occasional weekend visits a possibility.

\section{Presentation at Beginning of Therapy}

Tommy had never attended therapy before being mandated to treatment in the spring of his freshman year of college. During his first visit to the counseling center, he appeared embarrassed, as well as irritated, that he was required to talk to someone about difficulties in his life. Tommy commented that he would never have come to the counseling center on his own and apologized that I would be working with someone who was "forced" to be there. He reported that he had been feeling down lately and was not quite acting like himself, but denied that anything was seriously wrong. Tommy stated that he did not believe he was experiencing mental illness and, instead, indicated that he was merely reacting to and coping with the stress that other people in his life were putting on him. When asked if he felt depressed, he responded, "I don't think so. I think I'm just really pissed off these days and don't have the energy or the desire to be around people who can't handle me. I probably just need to man up and deal with it." Tommy reported that his drinking had gotten him into trouble on three occasions but did not think that his behavior was out of the ordinary for a college student. He stated that he was "just in the wrong place at the wrong time too many times" and it "caught up with him." Nevertheless, he indicated that his distress level was higher than ever before and that things had gradually gotten worse in his life after his girlfriend broke up with him in October. He expressed disappointment that his friends and family might see him as a "failure" and that before college he was accustomed to "winning at life." Although Tommy felt annoyed that he was in therapy, he stated that he wanted to pull his grades back up and improve relationships that had deteriorated over the past few months.

Despite his ambivalence towards treatment, Tommy maintained a respectful attitude towards me and listened attentively, even when it was clear that he did not agree with everything that I said. He reported that he was not sure that therapy would help him or improve his life but saw it as an intellectual opportunity to debate ideas and explain himself to someone who would be willing to listen. Tommy stated that he was not a "feelings guy" and was more interested in collaborative problem-solving than "endlessly dwelling on [his] emotions and getting stuck." I explained that there were a number of strategies we could employ to alleviate his distress and that it was important for him to tell me when he felt like things were not working. Furthermore, I acknowledged that I might ask him about his emotions at times and, as part of my job, push him outside of his comfort zone but would never make him do anything that made him overly uncomfortable or anxious. Tommy remarked that he liked to feel in control and was concerned that it would be hard to feel that way in therapy. I told him that this was his time and space and that I wanted to customize treatment to his needs in order for him to derive as much benefit as possible within the course of the semester.

\section{Diagnosis (Table 5)}

As shown in Table 5, Tommy met the DSM-5 criteria for Major Depressive Disorder, Single Episode, Moderate. For the past month, he had been experiencing a depressed mood most days for nearly half the day. In addition, he reported anhedonia, increased appetite, weight gain, 
hypersomnia, fatigue, concentration difficulties, and feelings of worthlessness. Tommy also presented with considerable anger and irritability. He denied having thoughts of death or suicidal ideation, planning or intent. Tommy also denied non-suicidal self-injurious ideation, planning or intent. He reported that his depression was making it difficult for him to get to out of bed and go to class and that he rarely had the energy to complete his assignments. Traditionally an "A" student, Tommy indicated that his grades were starting to drop in the "B" and " $\mathrm{C}$ " range. Furthermore, he stated that he was not enjoying socializing as much as usual and typically spent most of his time alone unless his roommates and friends pressured him into hanging out. Tommy reported that he was unsure if he was actually depressed because he was "just pissed off and annoyed at people most of the time, not crying and wallowing like most people do."

Tommy also met the DSM-5 criteria for Alcohol Use Disorder, Moderate. His self-report depicted a problematic pattern of alcohol use in which he drank larger amounts of alcohol over a longer period than intended, drinking alcohol in a way that prevented him from fulfilling major role obligations at school and home, continued alcohol use despite recurrent interpersonal problems caused and exacerbated by drinking, and recurrent alcohol use in situations where it was potentially physically hazardous. While he admitted that he probably drank more than he should and occasionally got himself into trouble after drinking, Tommy reported that he believed his drinking to be fairly normative for a college student and was reticent to see his consumption as a problem. Instead, he stated that he believed it actually helped him relax and cope with his depression and anger.

\section{Strengths}

Tommy presented with some strengths. Although he did not seek out treatment on his own, he recognized a need to work on himself and make improvements in his life. He possessed a moderate level of insight and demonstrated an adequate level of engagement in treatment. Tommy appeared to be highly intelligent, as evidenced by his academic history, and expressed a desire to do well in school in order to become a sports journalist. Even though he could be fairly opinionated, Tommy was respectful and open to feedback. During treatment, he demonstrated good interpersonal skills, which contrasted with some of his behavior that he described outside of treatment. Tommy reported that his social network was strong but worried that it would begin to deteriorate if he did not begin to make changes. He stated that he spoke on the phone with his mother sporadically and maintained a positive relationship with her.

\section{CASE FORMULATION AND TREATMENT PLAN}

\section{Formulation}

As a child, Tommy's closest male figure was his maternal grandfather who endorsed many traditional masculinity norms, including toughness, stoicism, pursuing success, and avoiding any behavior that could be construed as feminine. Although he loved Tommy and did a lot to care and provide for him, he was liable to steer Tommy towards traditionally male activities and chide him for exhibiting too much emotion, being overly clingy, crying, or "acting like a sissy." Such messages were further reinforced by his infrequent contact with his father. Like his grandfather, Tommy's father embodied many traditional masculinity norms. He was a 
risk-taking individual who drank heavily, gambled frequently, and rarely showed any emotions beyond anger and irritation.

On top of all of this, Tommy's media consumption consisted of sports and superhero cartoons, which emphasized ruggedness, athletic prowess, violence as an effective problemsolving strategy, and a need for domination. In turn, Tommy developed a cognitive schema that told him that his worth was dependent on upholding these norms and that he was a failure if he could not adhere to them. This schema was accompanied by attitudes, assumptions, and rules about why he needed to be traditionally masculine to be competent. As this schema strengthened, Tommy was guided by various "should" and "must" statements about how he needed to behave in order to "be a man." When his father would mock him for "being soft" or a friend would call him a "wuss," Tommy would have negative automatic thoughts that drove him to intensify his masculine behaviors to avoid further ridicule and embarrassment.

For many years, Tommy's mother served as a mitigating force by encouraging him to exhibit warmth, talk openly, and ask for help when he felt overwhelmed. Although this clashed with messages he was receiving elsewhere, Tommy remained particularly close with his mother and felt most comfortable when he was around her. From a young age, he had difficulty being away from her for too long and exhibited symptoms of separation anxiety disorder when at school, sleepovers, or with a babysitter. Tommy's grandfather and father were critical of how close the two of them were and would loudly state such opinions when Tommy was around. As he got older, his peers also began to mock him for being close with his mother and his fearfulness of being away from her.

By the time middle school began, Tommy had internalized the belief that his relationship with his mother violated the messages he had received about masculinity and felt that he needed to reduce the amount of time he spent with her. This detachment from his mother was painful but, over time, he poured his energy and focus into other activities and his environment rewarded him for excelling in academics, athletics, and social pursuits, instilling him with high selfesteem. However, despite these gains, Tommy's weakened relationship with his mother left him with few places where he could be vulnerable and open up without being questioned.

Throughout high school, Tommy continued to find success in academics, sports, and making friends. He felt successful, confident, attractive, and dominant. Peers, parents, and teachers revered him and used him as an example for others to emulate. Embodying these aspects of traditional masculinity aligned with his schema about how to be a man, resulting in high selfesteem and mostly positive automatic thoughts about himself. These boosts were amplified when he started dating Ashley and especially when he became sexually active. He was proud to have a girlfriend and lose his virginity before so many of his friends. On top of that, he also felt as though he could self-disclose and show emotion around Ashley more so than his male friends, allowing him to regain some of the positive aspects of his relationship with his mother that he had lost years ago. Socially comparing himself with others, Tommy felt like he was ahead of the curve and more successful than many of his peers. In short, Tommy's environment reinforced his behaviors, beliefs, and values. 
Once he moved to college, Tommy encountered a number of obstacles that led to a decrease in self-esteem and his sense of masculinity plummeted. He found it more difficult to succeed in his classes and had to work much harder to get passing grades. Tommy's athletic abilities were not considered as exceptional as they had been in high school, and he was unable to make the cut for the basketball team.

While his breakup with his high school girlfriend, Ashley, was already hard enough, it was compounded by the fact that he was cheated on and replaced with a new boyfriend, creating great shame and feelings of inferiority. Tommy's automatic thoughts told him that he was not living up to his attitudes, assumptions, and rules about being masculine, making him feel like an incompetent failure.

In reaction to these negative thoughts and feelings, Tommy's enactment of stereotypically masculine behaviors became more rigid. He was more likely to become angry and aggressive, he sought out hookups with female peers to regain feelings of attractiveness and sexual desirability, and he increased his alcohol intake in an attempt to dampen negative feelings, reduce social inhibitions, and express himself more openly. Although his drinking temporarily allowed him to feel free, engage in fleeting sexual encounters, and avoid negative thoughts about himself, he often felt more depressed in the aftermath. This pattern of behavior made it harder for him to attend his classes and maintain his grades, and his friends soon became irritated by his erratic actions. On top of that, he was getting into trouble and putting his enrollment status at risk. Failing to live up to his beliefs about masculinity, Tommy grew increasingly depressed and continued to drink, creating a cycle that prevented him from making meaningful changes in his life and further isolated him. Unlike high school, his college environment was not as rewarding of his attempts to embody traditional masculinity norms, instead punishing his rigid enactment of such qualities.

\section{Treatment Plan and List of Treatment Goals}

In order to address Tommy's unique presenting concerns, I selected a treatment approach that combined cognitive-behavioral therapy, motivational interviewing, harm reduction, and the core tenants of client-centered therapy. Bronfenbrenner's Ecological Systems Theory was also employed in order to explore the proximal and distal systemic forces impacting Tommy's experience. Treatment was broken into five phases, though it was expected that goals from each phase would likely overlap with one another and be addressed simultaneously at times. Given the short-term nature of Tommy's semester-long treatment, it was expected that that treatment gains would be relatively modest.

\section{Phase 1: Orientation to Treatment and Rapport-Building}

Treatment Goal 1: Provide Rationale For Treatment, Establish Rapport, and Create A Safe, Validating, and Nonjudgmental Environment

In light of the fact that Tommy was mandated to attend therapy and expressed considerable ambivalence towards participating, I knew that it would be important to properly orient him to treatment and make it feel as though it was a process from which he could benefit. Orientation and socialization to treatment has been found to be an essential component in 
fostering a collaborative, safe environment in which client growth can take place (McWilliams, 2004). Tommy had never taken part in any form of therapy in the past, so it would be crucial to provide him with information about the structure of treatment (e.g., number of sessions, length of sessions, etc.), the structure of CBT, and the extent to which confidentiality applied to our conversations. I wanted to inform him that homework would be assigned and why CBT considers it an integral aspect of therapy so that he did not feel blindsided and annoyed when he was asked to do something outside of treatment.

Furthermore, since Tommy appeared to struggle with being vulnerable, emotional disclosure, and help-seeking behaviors, it would be important to not push him outside of his comfort zone too fast. While it would be important to challenge and modify some of his internalized beliefs about masculinity, doing so too soon could damage rapport, make him feel pathologized, and lead him to mentally detach from participating in treatment. Instead, it would be necessary to make him feel like therapy was something he could take ownership of and exercise a sense of agency. I would need to create a safe space for him in which he could begin to open up and learn how to vocalize his pain and ask someone for help without feeling weakness or shame. Creating a strong, collaborative alliance would be an essential ingredient to a successful treatment.

\section{Phase 2: Targeting Alcohol Use}

Treatment Goal 2: Decrease Tommy's Alcohol Consumption Through Harm Reduction And Motivational Interviewing Strategies.

Addressing Tommy's dysfunctional pattern of alcohol use needed to take priority before addressing other issues since it was the reason that he was mandated to attend treatment. Furthermore, without managing such substance issues first, it would be difficult to target depressive symptoms or explore his beliefs about traditional masculinity norms. I believed that reducing, if not eliminating, Tommy's alcohol consumption would help him repair relationships with peers, attend class more frequently, complete his assignments to a higher standard, and avoid situations that could lead to disciplinary action, setting the stage for more positive reinforcement. Reduction in alcohol intake would also lead to physiological change that would make it easier for Tommy to attend to activities of daily living and feel a greater sense of accomplishment and competence.

Considering that Tommy exhibited a high degree of ambivalence about changing his drinking pattern out of the belief that his consumption was no different than his peers, I planned to employ motivation interviewing techniques. These strategies help clients consider their goals and values, think about how their behaviors impede them from achieving what they want, and understand the ways that treatment could help them (Persons, 2008). Using motivational interviewing would help Tommy wrestle with his ambivalence, identify the intrinsic and extrinsic value of reducing his alcohol intake, and take ownership over the change process. Along the way, I also planned to frame treatment through the lens of harm reduction to help Tommy explore the pros and cons of changing and identify beliefs related to drinking less. 
Treatment Goal 3: Provide Tommy With Psychoeducation About the Relationship Between Substance Use and Depression

A large body of research has identified a strong relationship between alcohol use disorders and major depression, with some even claiming a causal link exists between the two (Boden \& Fergusson, 2011). Alcohol use can exacerbate depressive symptoms through both social consequences and altered neurotransmitter functioning (LeMarquand et al., 1994). Despite the difficulties that Tommy encountered while drunk, he still appeared to view alcohol as a way to experience a positive mood, social connectivity, and a means to express a variety of emotions that he did not feel he could when sober. Psychoeducation about the relationship between alcohol and depression would help him understand that alcohol provides a short-term escape from negative emotions, while creating long-term impairments in academic, social, and personal functioning. Since he believed that his alcohol consumption was no different than many of his peers, it would also be important to discuss how different people have varying reactions to alcohol and one does not have to necessarily drink excessively in order to experience negative consequences.

\section{Phase 3: Targeting Depression}

\section{Treatment Goal 4: Decrease Depressive Symptoms} on the PHQ-9 to At Least Mild Range $(<10)$

I believed that a mixture of both cognitive and behavioral interventions would be needed to target and alleviate Tommy's depressive symptoms. Tommy was engaging in a variety of negatively reinforcing behaviors (e.g., drinking, skipping class, watching television) that allowed him to experience some short-term relief from his distress but hurt him in the long run. His grades were dropping, his friendships were deteriorating, his enrollment status was at risk, and he was developing an increased level of negative thoughts about himself. The more accustomed he became to this pattern of behaviors, the harder it would be to break the cycle of isolation and avoidance.

Behavioral activation emphasizes a functional analysis of a client's behavior by examining the factors that perpetuate depressive behavior and minimize the likelihood of more adaptive behavior (Leahy et al., 2012). Treatment that utilizes behavioral activation strives to help the client reengage with their environment to a greater extent by identifying and pursuing activities and other situations that will reliably provide rewards, while increasing self-esteem and a sense of mastery. In the case of Tommy, it would be necessary to help him understand how his vegetative behavior was negatively impacting him and work with him to find opportunities on campus to put his strengths and interests to good use. Having Tommy complete activity logs would provide him with insight into his current lifestyle and set the stage for future activity planning that could provide him with a more consistent schedule, as well as opportunities to plan rewards for himself. Ideally, behavioral activation would lead to an increase in class attendance, completion of assignments, and healthy social engagement.

While implementing behavioral inventions, I also wanted to address Tommy's negative cognitions, as they appeared to have a substantial effect on his mood, self-esteem, and choice of 
behaviors. Cognitive therapy looks at a client's automatic thoughts, intermediate beliefs, and core beliefs in order to hypothesize how they impact their emotions and behaviors (Beck, 2011). Tommy was prone to multiple types of cognitive distortions, including labeling ("I'm a failure" and "A real man wouldn't react like this"), fortune-telling ("I'm never going to find another girlfriend"), and personalization (“Ashley cheated on me and dumped me because I'm a loser"). Having Tommy complete thought logs outside of therapy would bring greater attention to these thought patterns and allow him to examine the validity of such thoughts. Through cognitive restructuring, he could begin to develop more accurate and healthy thoughts about himself.

\section{Phase 4: Addressing Issues Related to Traditional Masculinity Norms}

Treatment Goal 5: Provide Tommy With Psychoeducation About Traditional Masculinity Norms

Tommy's behavior, beliefs, and statements indicated that he had internalized a number of traditional masculinity norms which were negatively impacting him. I hypothesized that his beliefs about masculinity were correlated with his substance use and depressive symptoms and that psychoeducation on the topic would be an important component of targeting his distress. It would be important for Tommy to understand that boys and men who strongly endorse these norms also report higher levels of physical and mental health problems, greater relationship strife and dissatisfaction, educational and occupational impairment, and loneliness and isolation. Similarly, he also needed to understand how greater identification with these norms is correlated with fewer health promotion behaviors (e.g., wearing a seatbelt or attending regular medical appointments) and greater risk-taking behaviors (e.g., substance use, unprotected sex, and gambling). Tommy needed this basic information before he could start to consider how his beliefs about masculinity shape his thoughts and behaviors.

Treatment Goal 6: Decrease Tommy's Meanings of Adolescent Masculinity Scale (MAMS) Score by Helping Him Construct His Own Definition of Masculinity

It was crucial to assist Tommy in exploring his internalized beliefs about masculinity and help him consider which of these qualities were helping him and which were hurting him. His statements indicated that he valued strength, success, dominance, stoicism, sexual virility, and a certain level of recklessness. It was important that Tommy did not feel stereotyped for embodying traditional masculinity norms or feel stigmatized in instances when he did not. He needed to discuss what he liked and disliked about being male and explore and identify his values and goals in life. This treatment goal could not be achieved by demonizing masculinity or attempting to erase all of these beliefs and behaviors. Instead, I aimed to help Tommy in defining his own unique definition of masculinity that would allow him to flexibly employ a variety of adaptive behaviors. These behaviors would help him to exhibit a wider range of emotions; to build strong, egalitarian relationships; and to display vulnerability in situations where he may need help and support from others. I utilized an active, collaborative, and problem-solvingoriented approach to help Tommy achieve this goal. 
Treatment Goal 7: Decrease Tommy's Overall Distress Level Based on Achieving a "Less Than Clinical Significance" Range Score on the OQ-45

By addressing Tommy's alcohol use, depressive symptoms, and internalized beliefs about masculinity, I hoped to minimize his distress level and increase his level of intrapersonal, interpersonal, and academic functioning. Achieving "less than clinical significance" range scores on the overall scale and three subscales would represent a notable decrease in depressive symptoms and substance use, as well as an increase in healthy social relationships, academic achievement, self-esteem, and overall emotion functioning. Ultimately, this pattern of OQ-45 scores would signify that Tommy had successfully met all previous treatment goals.

\section{Phase 5: Termination}

Treatment Goal 8: Review Treatment Gains, Coping Skills, and Relapse Prevention Strategies

I wanted to give Tommy the opportunity reflect on his time in treatment and discuss what he felt he gained from the experience. It was important for him to have a chance to identify and celebrate treatment gains and highlight new coping skills that he obtained throughout his time in therapy. Maintaining these coping skills would serve as relapse prevention strategies and allow Tommy to become his own therapist outside of the counseling center. I hoped that this would also be a good opportunity for him to compare his new views on masculinity with those that he held prior to therapy. Although Tommy was mandated to attend treatment, I wanted him to reflect on how he was able to make it a valuable experience for himself and explore how he viewed therapy at termination compared to at the start of treatment. Lastly, it was important to review future treatment options in the event that he believed he needed further assistance.

\section{COURSE OF TREATMENT}

\section{Phase 1: Building Rapport}

Sessions 1-2: Provide Rationale for Treatment, Establish Rapport, and Create a Safe, Validating, and Nonjudgmental Environment

Tommy came into therapy with considerable embarrassment, frustration, and ambivalence. Even though he was mandated to treatment and had to be there, he still had the option of engaging with the experience or just showing up to sessions to put in the bare minimum effort. As such, I recognized the need to create a safe, validating, and nonjudgmental environment for him so that he could feel comfortable enough to self-disclose and locate a new sense of motivation to make needed changes. I needed to optimize the experience to meet his unique needs and lay the groundwork for personal growth.

After obtaining informed consent and explaining confidentiality and its limits in our treatment, I fully introduced myself to Tommy. I explained that I was a graduate student clinician and would be working with a supervisor on this case. I told him that the counseling center provided short-term therapy, usually no longer than a semester, and informed him that our intake session would be 90 minutes, while other sessions would be around 50 minutes. 
During the first session, Tommy spoke at length about his presenting concerns, romantic history, relationships with friends and family, academic performance, substance use, and other relevant biopsychosocial domains. He was nonchalant and emotionally-removed when describing his struggles, indicating a tendency towards minimization and intellectualization. Tommy appeared to be making efforts to come off as confident, unphased, and even a little arrogant. However, his nonverbal behaviors (e.g. shifting in his chair, intermittent eye contact, and fidgeting with a pen) suggested that there was some anxiety and discomfort beneath the surface. Nevertheless, he was cooperative and answered all questions asked of him, demonstrating some level of willingness to engage in the process with me. He listened politely when I spoke, occasionally grinning when he thought I was making an interpretation or, in his words, "pulling a psych move" on him. I noticed that he was guarded and concerned about moving too fast, and I made sure to let him speak without interrupting too much.

Throughout the session, I attempted to model appropriate behaviors and convey that I was listening to him and interested in what he had to say. I maintained steady eye contact, nodded my head to indicate that I understood him, and matched my facial expressions to the affective tone of what he was saying. I provided short rephrases to summarize what he had just said and make sure that I was understanding him correctly. This also gave him the opportunity to correct me and help me better comprehend the point he was trying to make.

Towards the end of the session, I thanked him for his willingness to take risks and trust me enough to disclose private information. I acknowledged that clients often feel awkward as they adjust to therapy and that it is a process that can feel uncomfortable at first. I validated his hesitancy to engage in the process but also stressed the need to make the most of the time since he was mandated to treatment and had to be there anyway. In order to increase buy-in, I summarized his own words to highlight problem areas and create a convincing rationale for treatment. Tommy was quiet during this part of the session, suggesting that he recognized that he had made his own case for why he should be in treatment but still was unconvinced that it would work. I gave him the opportunity to ask questions or voice concerns before we ended, but he just shook his head and said he would see me next Friday. He wearily thanked me on his way out the door.

At the start of session \#2, I asked Tommy how he felt after leaving our first meeting together. He told me that he felt some relief at having the opportunity to discuss his recent experiences out loud and in the form a coherent narrative rather than his usual haphazard way of ruminating. Still, Tommy noted that he felt vulnerable walking back to his dorm afterward, wondering if he had suddenly disclosed too much personal information too soon. He indicated some worry that I would see him as "a bad kid" and over-pathologize him. Tommy also reverbalized his belief that he did not need therapy because he had not consumed alcohol since last semester and was only there because he was being forced. I normalized this response to starting therapy and reassured him that we could move at whatever pace would make him most comfortable, while also validating that it was frustrating to be there to work on alcohol use when he had not drank in a few weeks. Once again, I emphasized that the therapy hour was his space to utilize and that it was important for him to have at least a partial ownership of the treatment process. 
I used this session as an opportunity provide a framework to our treatment. In order for Tommy to gain a better understanding of how our work would be structured, I gave a basic overview of CBT to highlight areas of intervention and explain terminology that I might use. Tommy mentioned that he had heard of CBT before but did not know how it worked. In order to succinctly illustrate the theory, I drew the CBT triangle on a whiteboard to explain the connection between thoughts, behaviors, and emotions. I explained that I would be asking him to explore biopsychosocial influences in his life that were impacting his presenting concerns. I told him that would also be asking him to consider how his relationships, media consumption, and overall experience in his community impacted his beliefs, values, and aspirations. Additionally, I explained that while I would be working primarily from a CBT lens, I also often integrated aspects of client-centered therapy, harm reduction, and motivational interviewing into my treatment, briefly explaining what those theoretical orientations entailed. Tommy was curious about what my treatment inventions might look like. Accordingly, I provided him with a brief overview of behavioral activation, cognitive restructuring, and mindfulness and relaxation techniques that I liked to use, while also acknowledging that I would be using other interventions and strategies as treatment progressed and I could better evaluate his needs.

By the end of this session, I recognized that it would be important to eventually provide psychoeducation to Tommy about masculinity norms and how internalization of such qualities could be negatively impacting him. While Tommy did not present as hypermasculine, he avoided emotional expression out of fear of being overly vulnerable; turned to substance use, sexual flings, and other unhealthy externalizing behaviors to cope with negative emotions; and endorsed traditionally masculine qualities like competitiveness, strength, aggressiveness, and stoicism. I hypothesized that his beliefs about being a man and his behavioral tendencies were closely related to his experiences with substance use and depression and would need to eventually be addressed. As a male clinician, I understood that it would be necessary for me to model a flexible example of masculinity and avoid making stereotypical assumptions about Tommy's beliefs, behaviors, and values. I wanted Tommy to be able to construct his own version of masculinity without my biases entering the equation. Although I had my beliefs about what constituted a healthy masculinity, it was not my place to impose those values or assumptions onto Tommy.

\section{Phase 2: Targeting Alcohol Use}

Sessions 3-5: Decrease Tommy's Alcohol Consumption Through Harm Reduction and Motivational Interviewing Strategies and Provide Him With Psychoeducation About the Relationship Between Substance Use and Depression

Although I believed that Tommy's depression and the internalized masculinity norms that impacted him were actually the most relevant issues in need of attention in his treatment, he was primarily mandated to attend counseling due to alcohol-related infractions that he had incurred on campus during the fall semester. I recognized that it would be difficult to adequately address and treat his symptoms and underlying beliefs if he was continuing to engage in maladaptive substance use during treatment, especially since he was at risk for expulsion if he got caught by campus staff again (Persons, 2008). 
I utilized session \#3 to get a history of Tommy's alcohol use, assess his attitudes, beliefs, and expectations about substance use, and more clearly understand the reasons for his use and that ways in which his behavior had negatively impacted him. Tommy reiterated that he had not consumed alcohol since returning for the spring semester and had not over the holiday break either. He stated, "I get that I'm coming here because I messed up with alcohol a few times, but I want you to know that I'm not an alcoholic. I made some dumb decisions and was at the wrong place at the wrong time." I agreed with him that he was likely not physically dependent upon alcohol but stressed that his use was nonetheless problematic and impacting his ability to thrive.

Tommy reported that he first drank alcohol during the spring of his senior year of high school. Prior to that time, he was involved with sports at school and feared that he could be kicked off of his teams if he got in trouble for drinking. Tommy indicated that he never got in trouble for consuming alcohol in high school and rarely got drunk. He stated that he was typically the designated driver for his girlfriend and refrained from drinking when they went to parties together. Tommy reported that he sometimes would have 4-5 drinks when he was hanging out in a group at one of his friends' houses but explained that these were always situations where he was sleeping over and never had to worry about driving. Speaking about this period in his life, he stated, "We got buzzed but we had a pretty good system for being safe. We always made sure we were in for the night if we were going to start drinking. If we were going to a party, we picked a DD ahead of time." Tommy estimated that he drank on roughly ten occasions before he began college. He reported that he was drawn to drinking towards of the end of high school because he had been focused on sports and academics for so many years and was looking for an opportunity to let his guard down and "be a little irresponsible" like many of his other same-aged peers.

Tommy was open about the fact that his habits changed when he got to college. He indicated that not playing sports gave him more time to socialize, and he did not have to worry about being kicked off of any teams. Furthermore, everyone with whom he socialized lived on campus, so there were never any concerns about driving or needing a designated driver. Tommy reported that these factors and the normative nature of drinking on campus led him to increase his drinking on weekends. He stated that he got drunk on most Fridays and Saturdays in the fall semester and that he rarely faced any negative consequences from this behavior except for the occasional hangover. However, he recognized that his drinking escalated even further after his breakup with his girlfriend and noticed that the way he responded to alcohol changed. Specifically, he reported that he was more likely to become irritable, angry, and argumentative after drinking, blackout, or vomit, whereas he had previously been someone who got "enthusiastic and goofy" and avoided negative physical consequences when he was drunk.

Tommy reported that he knew it was important for him to abstain from drinking or at least be especially careful if he decided to indulge. He frequently made reference to his annoyance that he had to be so cautious when his friends were "just as bad, if not worse" when it came to drinking. He described feeling frustrated and ambivalent, on one hand wanting to continue drinking and partying as if nothing had ever happened and on the other hand recognizing that his drinking was causing problems in his daily functioning. 
Drawing from motivational interviewing, I asked Tommy to assess the pros and cons of drinking alcohol (Persons, 2008). With regard to the pros of drinking, he identified being able to feel social and "lively" as a motivating factor. Tommy discussed how alcohol allowed him to push away his social inhibitions, which was especially helpful when he was around large groups of new faces or when he was trying to enter into a romantic encounter with a female peer. He stated that drinking made him feel like he fit in with his peers on campus and worried that abstaining from alcohol would make him stand out or cause others to question him. Tommy explained that alcohol also allowed him to get away from his sadness and anger about his breakup with his girlfriend and his ruminations about her and her new boyfriend, though he acknowledged that he often felt angrier and sadder at the end of the night than he had before, especially if he had engaged in an act that was likely to cause him embarrassment or shame the next day. Nevertheless, he indicated that he often turned to drinking in an attempt to mitigate these unpleasant emotions. Tommy also spoke about how drinking gave him an excuse to be more "wild" than he usually was and exhibit a sense of fearlessness.

Tommy was also able to be candid about the downsides that resulted from drinking alcohol. He noted that he had engaged in reckless behavior (e.g., going to bed drunk and vomiting in his sleep) that put his health and safety at risk.

Additionally, Tommy was aware that he had become irritable, aggressive, and nasty on a few occasions because of drinking and had upset many of his friends. Tommy became embarrassed when I reminded him that he was also written up for harassing a female peer at her dorm after drinking. "That's really hard for me to talk about. I'm pretty ashamed that I did that. I never wanted to be the kind of guy that treated girls that way." He reported that this was difficult for him to experience this level of interpersonal conflict and tension because he was always wellliked in high school and was unaccustomed to being on the receiving end of someone else's annoyance.

Furthermore, Tommy recognized that his weekday drinking made it harder for him to get up in the morning to attend class. He mentioned that he had also turned in a number of assignments late and was putting in minimal effort, which resulted in lower grades. He was also aware that he had put on weight that was at least partially attributable to drinking and admitted that this change negatively impacted his self-esteem. Most of all, Tommy understood that his drinking behavior jeopardized his ability to remain at college. Tommy reported that it was difficult to discuss these factors and "sometimes could not believe how different [he] had become since high school." He worried that he was becoming like his father and maternal grandfather who both became "jerks" when they drank.

When Tommy returned for session \#4, the first thing he did was disclose that he had consumed two beers with his friends on Saturday while they watched a football game on television. He reported that he was feeling guilty about his choice to drink and wanted to get it off of his chest. I let him know that I appreciated his openness and honesty but also explained that I was not going to admonish him or even tell him that he could never drink again. At the same time, I made it clear to him that I was not going to endorse his alcohol use since it was illegal but recognized that underage consumption of alcohol on college campuses was often widespread and seen by many as culturally normative. As is stressed in motivational 
interviewing, I discussed how it was important for him to want to change for his own reasons and that change would be unlikely otherwise (Neighbors et al., 2006). I asked Tommy what it was like to drink again outside of the guilt he experienced from doing so. He replied, "Fine, I guess. It was just three of us hanging around and not planning on going anywhere. When I started, I decided that I would stop after two drinks."

Tommy was continuing to wrestle with ambivalence about whether or not he should change his drinking behavior. I asked him to speak to this ambivalence and try to untangle the thoughts on which he had been perseverating lately. As mentioned before, Tommy lamented that it was frustrating to have to cut back or stop drinking when he was not consuming much more than his friends. Nevertheless, he understood that he was responding to alcohol in a more maladaptive way than his friends. Tommy discussed his fear that he would be left out of social events and shunned if he stopped drinking and did not know if his peers would accept him. At the same time, he explained that he was "not being the person [he] wanted to be" and was upset that he was doing poorly socially, academically, physically, and emotionally. Tommy described feeling like he was in a "downward spiral" and did not know if he could pull himself out of it without changing how he drank alcohol.

In line with the philosophy of motivational interviewing, I knew that Tommy would need to want to change his behavior on his own for his own reasons. Hearing my thoughts and opinions might have a short-term effect on his decision but was not going to alter his behavior for long (Graham et al., 2004). Tommy's decision to change would need to be line with his own goals and values and would have to come from a recognition of how his behavior was holding him back from attending to those goals and values (Neighbors et al., 2006). Although I thought Tommy would be particularly hostile to the idea of changing his alcohol consumption when I first met him, each additional conversation indicated that he understood that changing would provide some benefits.

Much like our conversation the previous session about the pros and cons of drinking, I used this session to ask Tommy about the benefits and drawbacks to changing how he consumed alcohol. I suggested he start with the drawbacks, thinking that listing the benefits second would be more impactful and overshadow his fears. Tommy indicated that drinking less or not at all could make it harder for him to comfortably socialize at large gatherings. He worried that he would be perceived as "weird" for not drinking and that others might automatically assume that he was not interested in attending certain social events without even asking him. Tommy reported that he found it hard to talk to unfamiliar female peers if he had not drank and worried that it would be hard to start dating again. He also described a fear that it would be harder to unwind and deal with his feelings of sadness and anger if he could not drink because that had become a primary coping method for him. Overall, Tommy's responses suggested a pattern of cognitive distortions that included all-or-nothing thinking, fortune-telling, and catastrophizing. I took a moment to briefly preview those concepts with him, explaining that I wanted to return to those themes in a future session more focused on cognitive work.

Next, I asked Tommy to consider some benefits that might result from a change in drinking. He laughed and stated, "Well, I probably won't get kicked out of school if I stop drinking." Tommy went on to explain that it would be easier to avoid risky and dangerous 
situations if he stopped drinking or only drank in certain contexts. He acknowledged that it would be easier to attend early morning classes, put in more time and attention on assignments, and improve his grades if he was not drinking as much. Tommy discussed how his friends would probably like him more if he changed and that it would give him the opportunity to repair some of the relationships with people he had upset or wronged during the fall semester.

On the topic of romantic relationships, he indicated that he would be a more attractive potential partner if he was not "a drunk idiot" at most social gatherings and that he would be less likely to engage in brief, awkward hookups that did little to improve his self-esteem. Tommy also spoke about how he wanted to get back in shape and see if there were opportunities for him to get involved in sports on campus, even if it was just at the intramural level. He noted that it was hard to go to the gym or want to get up and move around when he had been drinking because it sapped him of his energy and motivation.

I let Tommy know that I appreciated his willingness to engage in this conversation and consider what change might be like. I mentioned that good grades, strong friendships, and physical activity seemed quite important to him and recognized that it had been difficult for him to feel like he was succeeding in any of those domains lately, which ended up making him feel depressed and wanting to drink. I suggested that it might be helpful for him to write down benefits of change on a piece of paper or in his phone so that he always had a reminder if he wavered in his commitment to making healthier decisions. Tommy reported that he would create a note in his phone because it would be more private and he could have it with him wherever he went.

By session \#5, I decided to emphasize a harm reduction approach with Tommy rather than stress a need for total abstinence from alcohol. I understood that he already had a lot of motivation to change and could see the benefits of reducing his alcohol intake. Additionally, it seemed somewhat unrealistic to push an abstinence mindset on Tommy given the short duration of our treatment and the fact that he was a freshman on a college campus surrounded by peers who drank. Instead, I decided that it would be more relevant to nonjudgmentally implement an approach that aimed to reduce the harms of alcohol, while acknowledging that he might still choose to drink from time to time (Neighbors et al., 2006). I continued to be careful to avoid endorsing his alcohol consumption and refrained from any comments or reactions that could be seen as glorifying substance use.

Tommy informed me that he had not drank in between sessions. He stated that he stayed in Friday and Saturday night to get caught up on homework. Tommy reported that being productive and getting a good amount of sleep over the weekend helped to improve his mood but indicated that he felt lonely in the process and spent some of his time thinking about his exgirlfriend, which made him feel sad. I empathized with Tommy and agreed that making changes in one's routine could lead to a mixture of emotions. Furthermore, I stressed that his past alcohol consumption was only part of his presenting concerns and that there was more we could discuss in treatment.

An important aspect of harm reduction is social norms clarification, which aims to clear up misperceptions people have about trends in substance use that may motivate them to continue 
to consume at an unhealthy level (Graham et al., 2004). I provided Tommy with some quick statistics about alcohol consumption on college campuses in order to illustrate that students often overestimate just how much their peers are drinking (Neighbors et al., 2006). I explained that college students also underestimate levels of abstinence from alcohol on campus, as well as the level of acceptability that most students have when their peers choose not to drink. Additionally, I highlighted how many overestimate the social acceptability of drunk driving, choosing not to use protection during sex, and other reckless behavior that can result from binge drinking. Tommy admitted that he was surprised to hear these statistics and stated that it felt like most people around him drank heavily and that he knew very few classmates who did not drink at least occasionally.

Envisioning that this would be the last session in which we would primarily focus on alcohol, I presented Tommy with a list of coping strategies that he could use to continue to reduce his drinking behavior and the negative consequences that came from it. We went over the list of options and I had him select a few that he thought would be most helpful. Tommy reported that setting a limit of drinks prior to the start of a social occasion could help him plan ahead and indicated that he felt comfortable asking a close friend to assist him in sticking to that plan. I mentioned that some people found it helpful to decide on how many drinks they would have that night, put quarters in their left pocket to represent those drinks, and move a quarter from the left to right pocket each time they had a drink so that they could easily keep track of their consumption.

He stated that he also liked the idea of drinking more slowly and alternating between alcoholic and non-alcoholic beverages. Tommy indicated that he would try to avoid gatherings with large crowds that were likely to be noisy for the remainder of the year since they were most likely to attract the attention of RA staff and campus police. Additionally, he stated that he would try to avoid prolonged social events in which people could be drinking over extended periods of time (e.g., day drinking events), as well as drinking games that made it difficult to gauge how much you were drinking.

Towards the end of the session, I told Tommy that I wanted to move away from primarily focusing on alcohol in our next session and explore his depressive symptoms. In the meantime, I highlighted the strong relationship between alcohol use disorder and major depressive disorder, noting that reducing one's alcohol intake has been found to facilitate physiological changes that decrease depressive symptoms (Boden \& Fergusson, 2011). I discussed how it appeared that his depression was exacerbated by the social consequences of his drinking, as well as the ways in which it held him back from attending to academic responsibilities, his usual fitness regimen, and important activities of daily living like sleeping and eating a healthy diet. In short, alcohol had served as a short-term escape from negative thoughts and emotions that succeeded in causing more long-lasting problems in various major domains of his life.

Finally, to address his frustration that his drinking behaviors were not all that different than those of his friends, I reminded him that people have varying reactions to alcohol and one does not have to drink excessively in order to experience negative consequences. 


\section{Phase 3: Targeting Depression}

\section{Sessions 6-8: Targeting Depression Through Use of Behavioral Strategies}

Tommy arrived to session \#6 in a sad, muted mood. He reported that his past week had been going well and that he had successfully avoided drinking despite temptation. However, Tommy stated that he had been on Instagram earlier in the day and came across a new batch of pictures that his ex-girlfriend posted depicting her and her new boyfriend spending time with her family with whom Tommy had previously been quite close. He indicated that this occurrence made his breakup feel more "real and permanent" than it had before. I validated these reactions, noting how difficult it must be for him to view these pictures when he was trying to work on his mental health.

Although it was unfortunate that Tommy was experiencing such pain, it was an opportune entry point to working on his depression. When I reminded Tommy that we had talked about discussing depression today, he sighed and looked down at his feet. He said, "I know you want to talk about it and are really sure that I'm depressed but, like I said, I'm not sure that I'm depressed. I think I'm just reacting to some bad shit in my life." I acknowledged Tommy's discomfort with the term depression and explained to him that depression can result from one's attempts to manage too many stressors at once and that the term should not be thought of as a way to judge his success in dealing with his distress.

Tommy explained that he found it difficult to talk about his feelings openly and admitted that it was rare he did so with another male in the past. He reported that he had sometimes talked to his mother or ex-girlfriend about his emotions but refrained from doing so with male family members or peers out of fear of mockery. I spoke about how I had seen Tommy express anger and frustration in our past sessions and how that did not seem to be a problem for him. He reported, "Being angry doesn't feel as bad. It makes me feel a little stronger than being sad." Tommy stated that it was more important for him to problem-solve rather than dwell on emotions and that he did not think that it would be helpful to get "stuck on feelings" in therapy. I agreed that it was sometimes important to move to a problem-solving stance rather than just sit in negative feelings but that it could also be helpful to initially give voice to those feelings in order to be heard and understood. I also pointed out that, despite what he claimed, Tommy had not really been doing much problem-solving lately and was probably ruminating on negative thoughts and feelings more than he realized.

I asked Tommy to consider the reasons why he might be experiencing depression. He stated, "Well, obviously the breakup with Ashley is the big thing. Like we've already talked about, my drinking was probably making me feel depressed too." We discussed further factors that impacted his mood, and he reported that he worried about losing his friends and no longer being invited to social events. He stated that not living up to his previous academic and fitness standards was also hurting his self-esteem. While he enjoyed the new community he had made at college, Tommy mentioned that he was somewhat homesick and missed many aspects of his high school life, including his friends, family, teachers, and the activities at which he excelled. He contrasted his vast successes in high school with the struggles of college and stated that he felt disappointed in himself. Beyond college, Tommy indicated that he occasionally experienced 
sadness and anger related to his relationships with his family, highlighting his complicated relationship with his father as a prime example.

I told him that whether or not he wanted to call it depression, there were many signs that he was experiencing the type of distress that someone who met the criteria for depression would. I reminded him that he had endorsed experiencing depressed mood, anhedonia toward previously enjoyed hobbies and social interactions, increased appetite, weight gain, hypersomnia, fatigue, concentration difficulties, and feelings of worthlessness on both quantitative questionnaires and throughout discussions in our sessions. Furthermore, he reported frequent anger and irritability, which, while not DSM-5 criteria for major depressive disorder, are often key features in depressed males. Tommy sat in silence for a moment, recognizing that he had laid out a case for having depression without realizing it. After pausing, he said, "I guess that does make me sound like a depressed person, but I don't want to die or kill myself. I thought that was how depressed people were supposed to feel." I explained that depressed individuals often had thoughts of death or suicidal thoughts and sometimes made efforts to kill themselves but that it was not a necessary component of being diagnosed with depression.

I provided Tommy with brief psychoeducation about depression, explaining that there is a strong genetic component to the disorder. Tommy had previously mentioned that both his mother and maternal grandmother had experienced depression in the past. He stated that his mother attended therapy for a few years following her divorce and still took anti-depressant medication to his knowledge. Tommy reported that he had recently begun to suspect that his father was depressed as well but would never admit it or make any effort to attend therapy. I told Tommy that many people without a prominent family history of depression exhibit constellations of symptoms during a stressful and/or overwhelming period in their lives. He responded, "So am I double screwed because I have a family history and I'm going through some tough things?" I stated that his depression was not necessarily twice as bad but suggested that it was possible that his recent distress had activated an underlying genetic vulnerability to depression that he had not been aware of before. I briefly explained the stress-diathesis model of depression to him to illustrate this process (Monroe \& Simons, 1991).

I reviewed the CBT triangle with Tommy, which highlights the interaction among thoughts, behaviors, and emotions (Persons, 2008). I informed him that we would be discussing the behaviors part of the triangle over the next few sessions to explore whether there were actions he was doing or not doing that made him feel better or worse. I explained that the goal was to determine what was working well for him versus what was maintaining his depressive symptoms so that he could make needed changes in order to feel better. Tommy responded, "Obviously, the drinking was the big thing I needed to change." I agreed but noted that it would also be important to look at what was missing and not just what he was doing to exacerbate his symptoms.

Towards the end of the session, I provided Tommy with an activity log to complete over the following week. I educated him about how to complete it and how it could be a helpful tool in making needed behavioral changes in his life. I asked him to complete it as fully as possible, while acknowledging that there could be times in his day where it might be more difficult to do so. 
Tommy returned the following week for session \#7. To start the session, I did a brief symptom check-in. Tommy reported ongoing depressed mood and indicated that he was still not as eager to socialize or engage in hobbies as he had previously been. However, he stated that he was not overeating as much and that he had not gained any weight. Tommy reported that he was napping less during the days and his level of fatigue had lessened. He indicated that he was concentrating better in classes and able to get more work done than he had in the past few weeks. Tommy stated that his self-esteem was still fairly low but felt that the work he was doing in classes and in therapy made him feel more productive and proud of himself. He stated that the previous week had been average and that he had not gone out to socialize over the weekend. Tommy reported that he had three beers in his dorm on Saturday while he and two friends held a marathon viewing of the Lord of the Rings trilogy. He stated that he talked with his friends ahead of time about limiting his intake to one beer per movie.

I asked Tommy if he had completed the activity log homework assignment. To my surprise, Tommy had completely filled out the form, accounting for each hour of all seven days. I went over the log with him to explore the times during the week where he reported struggling the most. Right away, it was evident that Tommy was most depressed and angry when he was lying in bed and ruminating on things that were not going well in his life. Likewise, he reported that he experienced sadness on Friday night when he chose to stay in rather than go out to a party with his friends. On top of disengaging from social activity, he indicated that he did not do much with his night other than play games on his phone and wonder about what he was missing at the party. These feelings were exacerbated when a roommate came home around midnight to hook up with a girl in the room next door.

Tommy's activity log also highlighted how his long naps made him more groggy than reenergized and prevented him from getting work done. On the topic of homework, it appeared as though Tommy felt anxious and frustrated when he tried to do work that he had put off for a while. He stated that doing that work was usually a solitary activity, which occasionally made him feel lonely. Tommy reported that if he had completed an activity log the previous semester, the low points in his week would have been the mornings after heavy nights of drinking. He indicated that he had experienced considerable shame, embarrassment, and anxiety following such instances.

Although these activities all had some negative effect on Tommy's mood, it was clear that his time spent using social media platforms was the most noteworthy contributor to his sadness and anger. Tommy spent at least two hours a day on social media and, according to his activity log, rarely felt good following this activity. I inquired about why social media might be negatively impacting him to such an extent. Tommy admitted that he spent a lot of time on Instagram and Facebook looking at his ex-girlfriend's profile and comparing himself to her new boyfriend. He stated that he also would watch her "stories" on Snapchat, which often depicted her partying with her new friends or out on dates. Tommy indicated that much of this behavior was mindless on his part and recognized that such surveillance was making him feel bad about himself. He stated, "Ashley untagged me in all our photos together. I didn't, so they are still on my profile. It sucks knowing that she can disconnect from the relationship and I'm still hurting." Tommy continued, saying, "It's not even just the stuff with her. I see all of these people on social 
media in relationships and I feel like I'm missing out. All the guys that I follow look happy and confident, and I'm feeling none of that right now."

Next, we examined what went well for Tommy during the course of week. Despite saying that he was not enjoying social activity as much as he once had, I noticed that he reported high positive emotions when he went to dinner in the dining hall with his friends, as well as when he spent time playing video games and watching movies with them. Tommy identified going to the gym and working out as being important activities in his week. He stated that it was hard to get himself to go some days but he always felt positive afterward. Similarly, while he noticed that his mood was usually low while working on assignments, he experienced happiness and a sense of pride when he was able to finish a task with strong effort.

I commented that Tommy seemed to be happiest when he was around others, being productive, or engaging in physical activity. Conversely, he seemed to feel the worst when he was choosing vegetative avoidance and escape behaviors to try and cope with stressors in his life. While he was no longer drinking to the extent he once had, his occasional tendency to skip class, put off homework, mindlessly use the internet, oversleep, avoid social activity, and ruminate was negatively impacting his mood and maintaining his depressive symptoms. I reiterated how many of these behaviors provided short-term relief and comfort but exacerbated his distress over time, creating a cycle that made change more difficult. In short, he was experiencing negative emotions, coping with them in unhealthy ways, and then subsequently having negative thoughts about himself that decreased his self-esteem and further worsened his mood. Tommy sighed and sarcastically said, "So, basically I need to change my whole life if I want to be happy? Sounds easy."

I empathized with Tommy's concern that so much change could feel overwhelming and also highlighted that his statement was representative of his tendency to use all-or-nothing thinking. I explained that all change would have to be small and slow at first and that he could build up gains over time. It would be important for him to start to reengage with his environment and identify and pursue activities that rewarded him, increased his self-esteem, and led to a greater sense of mastery (Addis \& Martell, 2004). Tommy needed to immerse himself in hobbies, interactions, and pursuits that would remind him of his strengths and avoid those that he identified as hurting his mood.

For homework, I asked Tommy to complete another activity log and begin to schedule one to two activities each day that would be likely to increase happiness or positive self-esteem. Tommy remarked that it could be tough to fit such rewards into his day due to how busy he was but that he would try. I reminded him that he spent a considerable amount of time passively using the internet and napping and that these scheduled activities could fill their places in his daily schedule. Additionally, I underscored his tendency to be hesitant to engage in social interactions or academic tasks but later experience positive emotions when he pushed himself to do so. I stressed that he would need to motivate himself to take part in these activities before he actually felt like it, as depression can make even the smallest of tasks feel gargantuan (Beck, 2011). This concept of "acting as if" would be important for Tommy if he wanted to make lasting changes in his life and improve his mood. 
I began session \#8 with another symptom check-in to assess treatment progress. Tommy reported that his mood was getting incrementally better, though he noticed that he still experienced some occasional sadness during the evening hours. He stated that his anhedonia was reduced and that he was finding it easier to socialize and get work done. Tommy stated that his appetite was average for him and that he may have even lost some weight from his renewed exercise regimen. He indicated that his concentration was improving and that he was starting to feel a little better about himself. Tommy reported that he felt fatigued for about half of the days in the last week and took long naps to mitigate his exhaustion. Like before, he said that the naps actually made him more tired and prevented him from being able to fall asleep at a preferable hour.

Following the symptom check-in, we reviewed Tommy's homework assignment. His second activity log revealed similar findings to his first: he was happiest when he was active and productive and more depressed when he was alone, passive, or trying to work on assignments on which he had fallen behind. Tommy stated that he had been pushing himself to spend more time with his roommates, go to the gym, and work on homework despite not always wanting to do so. He stated, "There's a stubborn part of me that didn't want to do any of that but I think knowing I'd have to come here and talk to you held me accountable."

I noted that it looked like he was still engaging in excessive social media activity and that it continued to make him feel sad, angry, and hopeless. Tommy explained that he had actually refrained from looking at his ex-girlfriend's activity and temporarily hidden her from the "news feeds" of those social media platforms. Instead, he stated that he was spending more time looking at the profiles of female peers from both college and high school that he found attractive and with whom he would like to hook up. This activity made him feel bad because many of these individuals were not single and he would, in turn, compare himself negatively to their partners. When the individuals were single, Tommy indicated that he would have thoughts about them being "out of his league."

I used the opportunity to briefly ask Tommy about the benefits of having this hookup mentality. He reported that he was not yet prepared to enter into a new romantic relationship but craved the validation and self-esteem boost he imagined would come from having casual sex or "even just kissing." However, he indicated that he actually felt awkward and slightly embarrassed after his only two hookups last semester. Tommy said, "I know I shouldn't need to be like that. I don't want to be some shallow college bro. It's just tough to go from being in a relationship for a few years, to getting dumped, to having no consistent affection in my life. I used to actually feel attractive." I thanked Tommy for his candor and stated that I would like to return to this topic during a later session.

Tommy reported that he enjoyed scheduling rewards into his week and that it gave him a push to complete tasks that he otherwise would have ignored. He had made it a habit to schedule a trip to the gym Monday through Friday following time spent in the library. He said, "Working out doesn't sound like much of a reward but I really looked forward to it when I was stuck at a desk writing papers." Tommy reported that he would also schedule in time spent with friends or a movie night in his room for every major homework assignment he was able to complete. 
Additionally, in order to maintain responsible drinking habits, Tommy would allow himself to have one beer back in his room at the end of the night if he went out with his friends and abstained from consuming alcohol. I told Tommy that this last reward was not exactly what I had in mind when I assigned his homework but reinforced his commitment to avoiding drinking in risky situations that could have dire consequences. While it would have been preferential for him to not drink at all, I refrained from chastising him and, instead, focused on his progress.

I highlighted how Tommy's irregular sleep schedule appeared to be an ongoing issue that contributed to some of his depressive symptoms. I challenged him to hold off on naps between sessions, even when his fatigue was strong. Tommy was concerned that it would be harder for him to get work done or want to socialize if he did not nap during the day. I acknowledged that not napping could have that effect in the short-term but that his energy levels would most likely return to baseline if he implemented a regular sleep schedule and continued to exercise. I provided basic psychoeducation about the benefits of sleep hygiene, urging him to avoid electronics for thirty minutes before bed and try to aim for 7-9 hours of sleep each night (Brown et al., 2002). I also asked him to consider the ways in which he could make his room more comfortable to facilitate a better sleep. Tommy reported that he liked to keep the room cool at night and listen to music before bed and would attempt to do both of these things moving forward.

At the close of the session, I asked Tommy to continue to schedule pleasurable activities and consider the benefits of getting involved in activities on campus that would utilize his talents. I highlighted the fact that he was working hard to return to his baseline functioning and that he should be proud of gains even when they felt small and incremental. I inquired about whether or not he could foresee any obstacles that could hinder this progress. He indicated that he was still trying to make up some assignments from last semester and that it was easy for him to feel overwhelmed and defeated by the progress that still needed to be made. Additionally, Tommy reported that he had an easier time motivating himself some days compared to others and that there was still frequent temptation to drink or engage in more vegetative activity. I reminded Tommy that he was trying out a lot of new behaviors and that it was okay to have some days that were less productive than others, as long as it did not become a majority of the time like it had been before.

\section{Sessions 9-10: Targeting Depression Through Use of Cognitive Strategies}

Most of Tommy's depressive symptoms remained roughly the same between sessions \#8 and \#9. However, I noticed that he was reporting higher levels of self-esteem than before. When I asked him about this, he stated that he was feeling better about himself because it seemed like he was getting "back on track." He said, "I'm getting work done, I'm working out, and I'm spending more time with my friends than alone." Despite gains in this area, Tommy was still experiencing a nighttime depressed mood most days. He reported that he was trying to "act as if" and still socialized as much as he could, but underneath he still found himself feeling sad and demoralized much of the time. I asked Tommy if he had tried talking to one of his roommates about his experiences with depression but he tersely replied, "No, I'm still not quite there yet." 
Between sessions, Tommy made more progress in becoming active and motivating himself to engage with his environment. He reported that he had gone to all of his classes and, although he was still behind on some of his schoolwork, he had been able to speak to some of his professors and get leniency on how quickly he would need to makeup assignments. Additionally, when not working, Tommy was now spending most of his evenings with his friends and only drinking sporadically. He stated that his drinking behavior was deliberately contained to his dorm suite when things were quiet, and that his friends were mindful to keep all alcohol out of his bedroom in case there was an RA search. Tommy had also successfully avoided taking naps in the prior week in an effort to create a more normal sleep schedule. Like many college students, he was still going to bed quite late and often only getting six hours of sleep rather than the recommended 7-9 hours. Tommy reported that reward scheduling remained a helpful tool and gave him something(s) to look forward to each day, regardless of how grueling his schedule might be.

Since Tommy was making positive behavioral changes in his life, I determined that it was an appropriate session to switch gears and introduce cognitive work to his treatment. Orientating him back to the CBT triangle, I explained that I wanted to take some time to focus on his thoughts and how his thinking patterns affected his behavior and mood. Tommy questioned if it was really possible for someone to change their thinking in quite the same way that they change their behaviors. I noted that depressed people often focus on the negative aspects of themselves, others, and the world around them and filter out or discount more positive occurrences in their life (Beck, 2011). I explained that, while we cannot necessarily force ourselves to think a certain way, we have the ability to become more aware of our thoughts and question how valid they actually are.

I briefly described the model of core beliefs, intermediate beliefs, and automatic thoughts and how they were all related (Beck, 2011). Tommy hypothesized that he might have a core belief of "I'm not good enough." According to him, some of his intermediate thoughts included, "I need to have a girlfriend to be successful," "I should be able to handle all of this work without this much trouble," and "If I got back together with Ashley, all of my problems will be solved." Tommy identified frequent automatic thoughts such as, "I'll never get another girlfriend" and, "No one is going to like me if I stop drinking." Along with this discussion, I provided Tommy with a photocopied handout that detailed common categories of cognitive distortions and went over each one with him (Beck, 2011). He commented, "Fortune-telling is a big one for me for sure. I also do a lot of personalization and all-or-nothing thinking too I guess."

Following this discussion, I introduced Tommy to thought journaling and explained how it can be an effective tool for correcting maladaptive automatic thoughts. I spoke about how this activity allows us to bring greater attention to our thoughts that we might otherwise not really notice and examine the validity of these thoughts by considering the evidence for and against them (Persons, 2008). Through this mindful attention, I explained that we gain the opportunity to formulate new, more accurate cognitions that give us a more realistic and balanced view of ourselves, others, and the world around us. I suggested that Tommy might be repeatedly having similar types of automatic thoughts throughout the day without even noticing it. 
We used the remainder of the session to practice cognitive restructuring with an example provided by Tommy (see appendix for a copy of the automatic thought log). Earlier in the day, he stated that he had the thought, "I'm never going to be able to get all of this work done" and recognized that it was not the first time he had such a thought. I asked him if he could identify the type of cognitive distortion that he had just reported and, after looking over his sheet, he correctly reported that he was fortune-telling. Tommy indicated that this thought made him feel $70 \%$ sad and $60 \%$ defeated. His evidence for the thought was that he had put off a lot of work and that it could be difficult to complete all of it on top of his current assignments. He stated that he believed the thought 75\%. Countering the thought, Tommy stated that it might take him a while to get all of it done but it was still possible. He was making slow but steady progress and had already arranged a makeup timeline with his professors. Additionally, he reminded himself that it would be okay if he got less than perfect grades because he was trying to cope with depression. After weighing the evidence, Tommy reported that he felt $40 \%$ sad, $20 \%$ defeated, and $50 \%$ reassured. He stated that he only believed his original automatic thought $35 \%$. I explained that this exercise was not designed to completely undo all of his negative emotions. Instead, the idea was for him to become more aware of the thoughts that passed through his head and not become bogged down by unquestioned distorted thinking. Even feeling just a little better was an important change.

To finish the session, I gave Tommy the homework assignment of completing one cognitive restructuring exercise each day between sessions. I provided him with around ten copies of a thought log and encouraged him to do more than one a day if he felt motivated. Furthermore, I asked him to identify the type of cognitive distortions that he was using in each case. He replied, "This seems a little less natural than when I was just trying to change my behavior. I'm not sure this will work as well for me." I let him know that it was okay if he found that it was not as helpful and that the overall goal was for him to be more mindful of the thoughts that were passing through his head and consider how they influenced his behavior and mood. It would be important for him to draw attention to maladaptive thinking patterns that he engaged in and be more critical of these thoughts rather than passively accept them.

Tommy arrived to session \#10 in a grumpy mood. He presented as quiet and sullen, a far cry from his usual engaged and interactive self. When I asked what was bothering him, Tommy informed me that his father had reached out to him and told him that he would be visiting him on Saturday. He explained that his interactions with his father were uncomfortable because he found him to be critical, disinterested, and unsupportive. Tommy hypothesized that his mother had reached out to his father and mentioned that he was having a tough time at college. He said, "I'm sure he's only visiting because he's being pressured. He would never go out of his way for me otherwise." Tommy indicated that his anxiety about this visit had interfered with some of the progress he had made in therapy and that he was not being as productive or social as he had been pushing himself to be before. I validated Tommy's frustration that it felt like he was backsliding but explained that therapy is often non-linear and that there are starts and stops throughout. I asked Tommy if it might be more important for us to discuss his father's visit rather than cognitive restructuring this session. He declined, saying "I don't want to focus on that too much right now. As you'll see, that topic will be present enough in my thought logs anyway." 
We reviewed the thought logs that Tommy completed between sessions. Despite his previous concern that the exercise would feel unnatural, he had filled all ten forms given to him with little space left over. I remarked that he was putting in a strong effort with each homework assignment given to him and voiced my appreciation that he had become so invested in his treatment. He replied, "I decided that I might as well make the best of it while I'm here. I can hem and haw or I can see what I can get out of the experience." While Tommy still exhibited some ambivalence about treatment, it was clear that he had become invested in the process and was now taking ownership of his mental health.

Tommy's thought logs contained a number of automatic thoughts related to his romantic capabilities, academic progress, and his relationship with his father. Some of these thoughts included, "My dad will never understand what I'm going through. I can't talk to him about anything," "I shouldn't have gotten into this college," and "No one will ever date me if I can't get my life together." Collectively, these thoughts made him feel sad, angry, and tired. He was able to come up with counter thoughts, such as, "My dad might not be able to understand what I'm working on but that doesn't mean it's not important;" "I'll be able to handle this work eventually -- right now it's hard because I'm depressed;" and "I'm sure I'll eventually date someone else when I'm doing better." Tommy indicated that these new thoughts brought a modest change in emotion but stated that it was sometimes hard to truly believe that these more adaptive cognitions were valid. He said, "It was interesting just to pay more attention to what's actually going on inside of my head even if my new thinking didn't fully change those attitudes."

Tommy commented that he was most likely to have these maladaptive cognitions at night, when he was doing homework, and when he was alone and relatively inactive. He said, "It's mostly only during homework when it's not going well. I'd also say I have them when I'm on Instagram or something like that and start thinking about being single." As Tommy had identified in the previous session, he was quite prone to utilizing all-or-nothing thinking, personalization, and fortune-telling. However, after reviewing his homework, it was clear that he also frequently used catastrophizing and perceived small, temporary failures as indicative of a hopeless future without love, success, or purpose. I highlighted this tendency and stressed a need for him to develop a more realistic, less self-flagellating view of momentary struggles that would soon pass. I wanted Tommy to be kinder to himself and be able to experience his successes as prominently as he did his perceived failures.

Tommy let me know that he did not enjoy the cognitive work very much and that he found it somewhat awkward and uncomfortable to explore his thoughts with so much precision. I asked him if he felt vulnerable discussing his thoughts with me and he replied, "Yeah, it's not the easiest." I agreed that it could feel like a big breach of privacy to disclose one's private thoughts to a stranger, especially when they pertained to sensitive topics. Tommy added, "I liked learning about the different categories of thinking more than plotting them out on the log. I guess if nothing else, that gives me an opportunity to call bullshit on myself."

Although Tommy did not appear to enjoy or benefit as much from cognitive restructuring as he had from behavioral activation, I assigned another week of thought journaling for homework between sessions to reinforce the concepts once more before moving on in treatment. I believed that it was important for him to continue to scrutinize his thoughts and become 
increasingly aware of the categories of cognitive distortions that he was most commonly employing without even realizing. If nothing else, the exercise could increase his level of insight about how he views himself, others, and the world around him.

\section{Phase 4: Addressing Issues Related to Traditional Masculinity Norms}

Session 11: Psychoeducation About Traditional Masculinity Norms And Their Effect On Functioning

Tommy returned for session \#10 in a better mood than he had the week before. He reported that his father had cancelled his visit on Friday morning because "important business came up." Tommy said, "I know there was no business. I'm sure it had to do with a new girlfriend or some party that came up for him." He admitted that he was relieved that his father had not visited but indicated that he was also feeling angry and hurt by the last minute cancellation.

As I reviewed Tommy's homework assignment with him, I noticed many of his automatic thoughts pertained to his relationship with his father and touched on concepts of masculinity. These automatic thoughts included, "My dad doesn't like spending time with me because he doesn't think I'm cool or tough," "My family sees me as more like my mom than my dad," and "Do people not respect me because I'm not strong enough?" While Tommy was able to come up with more adaptive thoughts to challenge these initial cognitions, it was clear that he was perseverating on and wrestling with aspects of his identity that he felt were discordant with traditional masculinity.

I voiced these observations to Tommy and asked if he was aware of such a pattern. He replied, "I guess I always knew my relationship with my dad was a big issue for me but I never really saw my issues as having to do with being a guy." I explained that many people hold these beliefs about masculinity but often do not fully exhibit behaviors related to them until they are placed in a stressful situation and need to grapple with difficult, overwhelming challenges. In Tommy's case, I highlighted the fact that he was still transitioning to a new environment and was living on his own for the first time. On top of that, he was trying to cope with depressive symptoms in the aftermath of a painful breakup. In short, he was trying to make sense of this situation and turning to learned masculinity scripts that he had internalized throughout his life, perhaps without ever fully realizing that he was doing so.

I provided Tommy with psychoeducation about some of the research regarding IE-TMNs. I explained that those who held more traditional masculinity norms exhibited fewer health promotion behaviors, such as exercising, attending regular medical and dental appointments, or eating healthy foods. In effect, those individuals sleep less and have higher rates of heart disease, physical injury, disability, smoking and substance use, and premature death. Due to these struggles, many who subscribe to traditional masculinity norms have a more difficult time completing school, advancing in their careers, or holding a consistent job. Tommy joked, "Is this supposed to make me feel like I'm Scrooge and you're the Ghost of Christmas Yet-to-Come warning me about what my future could be if I don't change?" I was amused by his reference 
and laughed spontaneously. I let Tommy know that these were general findings and not necessarily definite outcomes for everyone with such a worldview.

I went on to explain that IE-TMNs were also associated with lower quality friendships and romantic relationships, as well as less intimacy in those relationships. I informed Tommy that the research suggested that these relationship struggles were attributable to masculinity's emphasis on emotional restriction, self-sufficiency, and isolation. These qualities make it difficult to build lasting connections with others and contribute to interpersonal conflict. Many men who hold traditional beliefs about masculinity worry that self-disclosure, vulnerability, and help-seeking are non-masculine even though they are often necessary components in navigating life's stressors. In turn, relationships tend to suffer and problems that these men are dealing with are never fully addressed.

Additionally, I spoke about how males with IE-TMNs experienced more pronounced mental health difficulties. I asked Tommy if he could guess why this might be. He replied, "It's a lot of pressure to be a dude. There's a lot of expectations that you have to live up to and if you can't people make fun of you. Now you're telling me that people who do live up to them also have problems, so damned if you do damned if you don't." I agreed that our society's views on masculinity created unrealistic standards and that working hard to live up to them or failing to could both cause distress. At the same time, I questioned whether one could realistically fulfill all of the components of being traditionally masculine.

I continued and informed Tommy that research indicated that IE-TMNs were associated with greater depression, anxiety, and anger, as well as lower self-esteem. In turn, many males turn to risky behaviors such as gambling, substance abuse, and casual, often unprotected, sex. Tommy indicated that this last bit made him think about his father and reinforced his belief that his father had his own hidden struggles with mental illness.

Tommy reflected, "This is a pretty bleak picture of men. You're making it sound pretty hopeless for us." I stated that I did not think that it was completely hopeless situation for boys and men with these values. However, I indicated that it was sometimes difficult to provide assistance to such individuals because those who subscribe to such beliefs are less likely to seek professional help when they are struggling and in pain. Due to masculinity's emphasis on strength and dominance, many boys and men find it difficult to relinquish control in therapy and trust another person enough to help them. These individuals are more likely to downplay the severity of their symptoms or negative emotions and may make efforts to appear healthier than they are. In turn, many professionals and researchers have come to believe that fewer men are struggling than is actually true, creating a cycle where it becomes even harder for boys and men to seek treatment because there is an attitude that their struggles might be less pronounced compared to those of women.

Building on this misconception that males are suffering less than women, I explained that many boys and men that inflexibly hold these beliefs experience elevations in depressive symptoms but may not be properly identified by mental health practitioners due to the way in which their symptoms manifest. For instance, because traditional masculinity scripts forbid vulnerability, many males exhibit anger, irritation, and frustration rather than sadness when they 
are depressed. Since anger is not a DSM-5 criterion for depression, many skilled therapists fail to view more externalizing behaviors as an indication of depression. Additionally, I discussed how many depressed males manifest psychosomatic symptoms, which are more likely to be addressed by a medical doctor than a mental health professional (Martin et al., 2013). I highlighted how, ultimately, this assumption that boys and men are depressed less often, coupled with the reality that they receive less therapeutic attention, is particularly concerning given than males are more likely than females to successfully complete suicide (Emslie et al., 2006).

I acknowledged that I was providing Tommy with a lot of information all at once and reminded him that these were just trends. While many of these traditional masculinity norms transcend time and culture, I explained that there was variation across different groups of males and that not everyone who holds such beliefs will experience all of these negative consequences. Furthermore, I emphasized that certain aspects of traditional masculinity could be quite positive when exhibited in moderation and with flexibility, such as the drive to take care of and provide for others (APA, 2018). Nevertheless, I stressed that inflexible adherence to and enactment of these values was typically found to be detrimental to one's daily functioning and overall health.

Tommy was intrigued by the subject matter but also said, "Do you really think this is what I'm dealing with right now? I know I used to be a jock and come off as sort of a bro but I'm definitely not the typical meathead you see around campus or at the gym." I agreed that he was not the stereotypical image of hypermasculinity but stated that I had noticed him struggling with a lot of the traditional values associated with masculinity and believed they were particularly interfering with his ability to mitigate the stressfulness of the situation he was finding himself in at the moment. I told Tommy that I would like to continue discussing masculinity in future sessions, as I believed that it would be important for him to explore his identity and consider the values and attitudes that were more important to him and would be most helpful in allowing him to move forward and live a fuller life. Tommy agreed to this and stated that I had given him "a lot to think about" between sessions.

\section{$\underline{\text { Sessions 12-14: Identity Exploration and Reconstruction }}$}

Tommy arrived to session \#12 in a positive mood. He reported that he was nearly on top of all of his schoolwork and beginning to feel less burdened by assignments. He stated that he had not drank any alcohol in the previous week, was spending more time with his friends, and had even met a girl in his biology class, Lucy, whom he was considering asking on a date. Tommy indicated that he was still experiencing mild nighttime depression and usually took about an hour to fall asleep. Of note, he stated that he had a long conversation with his mother on the phone over the weekend and opened up about his progress in therapy, including our recent discussion about masculinity. He said, "I told her that I had never thought of myself as a typical guy. She said, 'You weren't always, but your father and Papa made sure that changed over time." Tommy reported that his mother went on to claim that it would have been hard for him to grow up without internalizing traditional beliefs about masculinity given his environment.

I knew that it would be important to continue this discussion about traditional masculinity with Tommy in a collaborative manner. Rather than use terminology such as "toxic masculinity" that places an automatically negative connotation on being male, I believed that it would be 
important to stress a need for "healthy masculinity" in order to highlight that masculinity could be positive (APA, 2018). I wanted to portray masculinity as a multifaceted, fluid concept that Tommy could define for himself rather than resort to traditional, inflexible definitions. Ideally, Tommy would fashion his own definition of masculinity, which would be informed by his personal beliefs, values, and worldviews rather than what others told him was important.

When asked what he believed it meant to be male, Tommy stated that he thought it involved being tough, composed, independent, successful, and rational. He mentioned that he always associated manliness with sexual virility and being able to seduce attractive women. Tommy said, "I grew up watching James Bond movies. Who was manlier than him? He lived on the edge, drank and smoke, slept around, and won all the fights." Tommy reported that he felt particularly masculine when he lost his virginity before all of his friends and received positive recognition for the milestone. He went on to voice that "real men" were usually not afraid of conflict, could handle most problems on their own, and, more often than not, were athletic. Tommy stated, "I don't know if I really think all of these things are true but I think they are the messages that I was given about being a guy."

Building on his statement, I inquired about where he thought he got these messages from. "Obviously my dad and grandfather like I've said a bunch now. They always thought of themselves as being super tough but now I'm thinking they were probably being pretty fake and trying too hard to cover up their emotions and fears because they didn't think they should talk about it. Outside of them, it feels like I learned this stuff from everywhere I went." Tommy spoke about how his friends would make fun of him for spending time with his mother and call him "gay" when he expressed interest in games, movies, or shows marketed towards girls and women. He discussed how various coaches in his life emphasized a need to be tough and play through pain. He remarked, 'I'm not sure how guys aren't supposed to take in these messages. Even if our parents didn't push these ideas, we'd have the rest of society telling us how to be manly."

I asked Tommy to consider the pros of being masculine. He stated that it felt good to be strong and in control. On the topic of success he said, "It's great when you can aim for a goal and push yourself to work hard to reach it, especially if you can do it on your own. I get that it's not always possible to do everything on your own though." He stated that he liked being perceived as attractive by female peers and felt a sense of pride when he succeeded in hooking up, as it signified that others saw him as worthwhile and desirable. Tommy reported that he did get some enjoyment from getting drunk with his friends and suggested that such occasions made him feel and appear fearless and reckless. Despite recognizing the harm that had often come from his drinking, he indicated that this behavior could be reinforcing because it made him feel appropriately masculine. He stated, "I guess I never consciously worked to be super manly or anything. Maybe those things that I tried to be were actually these qualities you've been telling me about and I assumed that they were just natural things all guys wanted."

Following this discussion, I asked Tommy if there were any aspects of traditional masculinity that he did not like as much. He reported, 
"I don't like that it's considered girly to be close with your mom. My mom and I used to be really close but I'd get made fun of by my friends a lot for how much time I spent with her. It wasn't even just them. My jackass father would give me shit too. Now I'm realizing that he was probably just jealous."

He stated that he did not enjoy being around males that tried to "act tough all of the time," and that he sometimes grew tired of the tendency for male peers to relate to each other through gentle ribbing and/or insults. Tommy said, "It can be funny for a bit but after a while it just feels like some guys don't know how to connect otherwise." Tommy voiced that he also disliked feeling as if he had to hide his emotions from male peers and adults or run the risk of ridicule, especially when he was with his father. He stated, "You spend so much time trying to act composed and avoid anything that could be made fun of that you end up having no real personality."

I validated Tommy's statements about how there can be positive and negative aspects of traditional masculinity. Additionally, I reiterated my belief that his recent increased expression of more masculine attitudes was attributable to struggling in a new environment, dealing with a painful breakup, and coping with depression. Whereas his self-esteem in high school was elevated due to his academic, social, and extracurricular successes, his identity was fragmented when he arrived to college and was not naturally rewarded and reinforced in the same way. Being dumped by his girlfriend removed another prominent reinforcer in his life and led him to explore new ways of being rewarded by his environment based on how he believed males should act in such situations. However, Tommy's excessive substance use and negative consequences from it impacted his grades and relationships and further exacerbated his depression.

For homework, I asked Tommy to call his mother again during the upcoming weekend and check in with her. I let him know that I believed reengaging that relationship was important for him, as his mother had previously served as his biggest support figure and could help him practice being vulnerable, expressing emotions more openly, and asking for help. Tommy agreed to this assignment and stated that he could depend on his mother to be nonjudgmental and understanding with what he was going through.

Tommy and I spent most of session \#13 discussing how he used social media. He arrived to the session in a somber mood. Tommy briefly discussed his homework assignment and stated that he had called his mother as asked. He reported that the call went well and he was able to continue to talk with her about some of the topics that we were discussing in treatment, including masculinity. However, outside of the call, Tommy indicated that he was feeling sad because he had unblocked his ex-girlfriend on social media because he felt tempted to check up on her. After doing that, he came across pictures of his ex-girlfriend at a restaurant with her new boyfriend, her parents, and his parents. Tommy said, "It sucks just to see the two of them together but it hurt even more seeing the new guy spending time with her parents. When we were dating, they had basically become a second set of parents for me." I empathized with how upsetting it must have been to see those pictures and then perseverate on them afterward. I asked Tommy what led him to unblock his girlfriend. He replied, "There's a part of me that hopes to see that they are no longer together. I guess I'm still holding onto hope that there's a chance that we could get back together one day." 
I asked Tommy to talk a little bit about what his social media activity typically looked like. Recently, he stated that he spent a lot of time looking at his ex-girlfriend's profile, as well as her new boyfriend's. Tommy said, "At first, I thought I was doing it to make myself feel better and reassure myself that I was better looking than that guy or more fit. I realize that I was probably actually putting myself down instead of building myself up." As he had discussed before, Tommy also described a tendency to look at profiles of female peers that he was attracted to, wanted to date, and/or wanted to hook up with. Tommy spoke about the thoughts that he would have during this pursuit and stated that he often worried that these women would not find him attractive or sexually appealing. He said, "After that, I'd start worrying about my body and question what I even had to offer."

Tommy also described many of his friends posting pictures of themselves partying and hanging out in large groups. He said, "People like posting pictures that make them look fun and wild, at least at this school. I also think that it's an opportunity to show off how many friends you have." Tommy stated that he also followed a variety of public figures on social media, including, "The Rock," LeBron James, Leonardo DiCaprio, and Donald Trump. He stated, "I don't like Trump. I just follow him because he's ridiculous and says these wild things."

Throughout this discussion, Tommy spoke a great deal about the profiles of other male and female peers, as well as celebrities and athletes that he followed, but I was not hearing much about his own social media persona. Tommy reported that he was more of an observer on social media and did not do a ton of posting himself. He stated that his social media profiles were mostly filled with pictures of him that other people had posted. He said, "I don't even like to look at my profiles. They look like memorials to my relationship with Ashley at this point." When I asked him to clarify what he meant by this, Tommy stated that most of his pictures featured the two of them together throughout the years of their relationship. He stated that she had "untagged" herself from all of the photos since their breakup. Tommy said, "I haven't untagged myself yet, which I guess is a problem. I just don't want to erase them from my profile as if they never happened."

I noted that it seemed as though social media usage was a fairly passive activity for him and that it sounded like he usually felt depressed, anxious, or angry during it. Furthermore, I pointed out that he was describing a pattern of negative automatic thoughts that frequently arose during social media usage. These thoughts appeared to be comprised of negative sentiments about his physical fitness, attractiveness, and level of likeability/desirability. He replied, "Yeah, I could probably fill a few thought logs with what pops into my head when I'm on Instagram." I reminded Tommy that he had previously identified holding a core belief of "I'm not good enough" and questioned how much his recent social media usage activated this belief. He stated, "I think it has. It makes me wonder why I keep going on these sites if they make me feel this way." Tommy was able to recognize that these automatic thoughts about himself and his ability to make friends and find a romantic partner could be classified as catastrophizing and fortunetelling. I referred back to the CBT triangle and commented how Tommy's social media usage led him to have negative thoughts and subsequently experience unpleasant emotions. I asked him what behaviors followed and he stated, "Well, sometimes it makes me want to isolate and shut out the world. Other times, it makes me want to drink or just go to bed." 
I provided Tommy with some basic psychoeducation about how social media platforms are often quite successful in spreading, popularizing, and reinforcing traditional masculinity norms. For instance, I described how both males and females selectively choose and edit images of themselves in an artificial way that allow them to create an online persona which will lead to favorable social comparisons (Tifferet \& Vilnai-Yavetz, 2014). In the case of males, many choose to emphasize muscularity, fashionable clothing, and material possessions such as cars in their selected photos. These photos often depict them striking a pose or stance that makes them look aloof and not overly eager or happy. The hope is that they will appear indifferent, stoic, cocky, and/or tough. Tommy said, "Oh, my friends definitely do that. They totally think they are being badass when they post pictures like that. I've probably done it too now that I think about it."

I explained that, in the process of selecting what pictures to post online, these individuals edit out any photos that do not stress such traditionally masculine attributes, in effect giving their online friends and acquaintances an incomplete view of their lived experience in order to emphasize desired qualities. Tommy said, "When I think about it, I realize that the stuff on Instagram is fake. Most of the time, I don't question it though and take it as how the world really is." I agreed that social media could be insidious in how it makes certain behaviors or qualities appear natural and commonplace rather than meticulously and purposefully constructed. In effect, those that use social media often believe that the images they see of their peers are realistic and portray desirable qualities that are easier to replicate than they actually are.

At the end of our session, I asked Tommy to try and limit his social media usage in the coming week. For homework, I challenged him to only use such sites for 30 mins each day. I encouraged him to be purposeful and budget it into his day like he did with rewarding activities. I believed that there would be some benefit to not only limiting use but also setting specific start and stop times for usage. Tommy agreed and said, "Most of the time I'm on it I get sucked into it and lose track of time. Sometimes, I just open up one of the apps on my phone without even really thinking about it." I believed that this was another passive, vegetative activity in Tommy's life that was continuing to contribute to depressive symptoms and the internalization of traditional masculinity norms. Although I knew it might be unrealistic to aim for total abstinence of social media usage, I wanted Tommy to be more mindful about how he used these sites/apps and become aware of the sorts of thoughts he experienced during usage.

I also addressed the fact that there were only three more weeks in the spring semester, meaning that our treatment would need to come to an end soon. Tommy replied, "I know, it's been in the back of my mind. I'm actually feeling kinda bummed about it, which is funny because I didn't want to come here in the first place." I stated that I too would miss our sessions and that it is often hard to end treatment after getting deeply involved in the work. I acknowledged that he had been putting in a lot of work during our sessions and between and that I appreciated his efforts despite his initial reticence to take part in therapy.

Given that our treatment together would be winding down soon, I knew that session \#14 would be our last session primarily focused on Tommy's masculine identity and how it was impacting his presenting concerns. During the session, I wanted to stress the idea of Tommy creating his own version of masculinity that best suited his goals, values, and beliefs. In order to 
do this, I would need to be collaborative and avoid appearing judgmental or coercive in my desire to guide him towards a more flexible identity.

Tommy was in an upbeat mood at the start of the session. He stated that his mood had continued to improve over the past week and that he was sleeping better. Additionally, he reported that he was able to limit his social media usage between sessions and found that he did not miss it as much as he thought he would. Tommy said, "I had to keep reminding myself not to go on Instagram and Snapchat because I would just pick up my phone and start to open the apps without even really thinking about what I was doing." He remarked that he was more productive than usual because he was not on his phone the whole time and spent more time hanging out with his friends. I agreed that it was easier to engage with our environment when we were not isolating ourselves on our phones and how, paradoxically, our attempts to be social on our phones actually often made us more solitary.

After our conversation about social media, I returned to the theme of traditional masculinity norms and asked Tommy if he had noticed himself having any more thoughts about what we talked about in the last few sessions. He said, "Yeah, I'm seeing the masculinity stuff all over the place now. I'm seeing it on TV and when I'm spending time with groups of other guys. It's crazy how there are so many things in our lives we don't question." Like the work we did on cognitive restructuring that asked Tommy to become more aware of his automatic thoughts, I emphasized a need for him to become cognizant of the messages and attitudes he was internalizing and consider whether they were in line with his personal goals, values, and beliefs.

I asked Tommy what it would be like for him to try and live differently and be more flexible in how he enacted his masculinity. He replied, "Obviously I'd be healthier based on everything you've told me but I do worry about how people would see me, as sad as that sounds." I underscored the fact that Tommy did not need to completely reinvent himself or make himself a target to others. Pushing back against his fears, I suggested that it might even be possible that some of the changes he could make would lead to others enjoying his company more and growing closer to him. I believed that acting more authentically would make him more comfortable in social situations and open up the possibility for genuine connections with others, either as platonic friends or romantic partners.

Tommy spoke about how it was important for him to make some changes because he was fearful that he would eventually "turn into" his father or grandfather if he stayed on the same life course. He said, "It was fun being the cool athlete with the girlfriend who could deal with everything successfully on his own during high school, but that doesn't really feel realistic anymore."

I asked him what his ideal masculine identity would look like, suggesting that he should consider what norms and attributes he would like to keep, discard, or modify. He stated, "I still want to be someone who works hard, can show strength in times of conflict, and can provide for others." However, Tommy also discussed how he wanted to be able to talk about his feelings more openly with his friends and ask for help when he was struggling. He noted that his friends would probably be more receptive to these behaviors than he realized. I voiced my belief that he could even serve as a healthy model for his peers by demonstrating his openness to such 
behaviors. Tommy spoke about wanting to refrain from enacting the stoicism and reckless externalizing behaviors of his older male relatives.

On the topic of sex and romantic relationships, he said, "I also understand that hooking up with a million girls on campus isn't going to make me feel better about the Ashley breakup. It's not really the sex I'm missing, it's the comfort of being in a close relationship and having a companion." He also spoke about his ongoing disgust over getting written up for pursuing a female peer for a romantic encounter last semester. Tommy said, "I was acting so entitled when I figured that she definitely wanted to hook up with me just because we had before." He stated that he wanted to act more "chivalrous" towards woman on top of other desired changes that he had already voiced. I reminded Tommy that changing one's identity was not something that changed overnight and it would likely be an ongoing process that required frequent reflection and mindfulness.

In the spirit of fashioning a healthier, more flexible masculine identity, I suggested that Tommy might benefit from rebuilding and strengthening his relationship with his mother. Throughout his life, his mother had served as a positive support who nonjudgmentally allowed him to express himself openly and strive for whatever was most important to him. She did not try to steer him in a self-serving direction for her own narcissistic needs or hold him to traditionally masculine standards. Instead, Tommy's mother unconditionally accepted him and gave him an outlet to authentically disclose struggles and emotions.

Tommy agreed and said, "I think I need someone like her more now than ever. Maybe homesickness was a bigger part of all of my issues than I realized." I encouraged Tommy to try and set up a recurring weekly phone call with his mother to maintain that relationship, get the support he needed, and feel less alone. Given that the semester was winding down and he would be returning home soon, he stated that he would like to carve out one day a week where his mother and he spent time together. I supported this idea, believing that his mother could serve as a strong protective factor as he transitioned back to homelife and attempted to maintain gains he made over the last semester.

Overall, I highlighted a need for Tommy to keep expressing a wide range of emotions and be honest with himself and others about what he was going through. I stated my belief that having the opportunity to be more open and forthcoming in therapy had contributed to his improvement over the past couple of months. He agreed and said, "As much as I didn't want to need help from other people, I obviously needed it." I encouraged Tommy to find a balance between seeking help during tough times and maintaining autonomy and self-sufficiency when it was realistic. I noted that having the opportunity to manage one's own problems could be empowering and contribute to positive self-esteem under the right circumstances but that overreliance on oneself could make it difficult to recover from a stressful situation at times. Ultimately, I explained that I wanted him to create his own definition of masculinity that would make him flexible and open with how he interacted with his environment and navigated stressors.

I reminded Tommy that we would only have two sessions after this one. Between sessions, I asked him to consider how he would like to use our remaining time together so that he 
could address any final issues or concerns. He said, "I'm getting a little nervous about not having this time to talk each week once the summer starts. I think it'll be good for me to use our next two meetings to go over ways that I can prevent myself from losing all of this progress when I leave campus." I reminded him that he could seek treatment over the summer in the community if he felt as though it was necessary, but he stated that he was not ready to restart therapy with a new clinician yet and wanted to see how he could manage on his own for a bit.

\section{Phase 5: Termination}

Sessions 15-16: Review Treatment Gains, Coping Skills, and Relapse Prevention Strategies

Session \#15, our penultimate meeting, marked the beginning of the termination phase of Tommy's treatment. I knew that it would be important to give Tommy the opportunity to explore and review his treatment progress, while discussing areas in which he felt as though he still required more progress. It was important that he recognize the hard work that he had done and give himself credit for the large effort that he put into the process.

Based on the outcome measures that Tommy filled out throughout treatment, it was apparent to me that he had made considerable progress. He was reporting greater life satisfaction and fewer depressive symptoms. Furthermore, it appeared as thought he was becoming more flexible in his masculine identity and not identifying as much with traditional norms as he once had. I could also tell that he was becoming more reflective about his personal values and goals and how his behaviors were informed by such qualities. Additionally, based on our conversations, it also sounded like Tommy was drinking far less alcohol than he had been during the previous semester and was utilizing the harm reduction techniques we had discussed earlier in treatment to decrease the likelihood of negative events resulting from his decisions to drink.

During the early portion of the session, Tommy discussed recent events in his life and reported that there was one night where he had drank three beers with his roommates. He stated that he allowed himself this experience because he knew that they would be staying in and it was a smaller group. Tommy reported, "We were just sitting around in the common room watching a funny horror movie from the 1980s. I knew we wouldn't be leaving or heading to anything larger that would attract more attention." Tommy also spoke about going on a "casual date" to an ice cream shop off campus with a friend from his "Introductory Geology" class. He said, "It was nice but I don't think it's going anywhere. At the very least, it felt good to be spending time with someone new and pushing myself to do something outside of my comfort zone."

After catching up on what transpired between sessions, I asked Tommy how he felt knowing that he would be ending treatment with me after our next session. He said, "I'm going to miss it more than I thought I would, but I'm proud of myself for making as many changes as I have." Tommy stated that he was feeling less depressed than before and happy to be doing better in his classes. He indicated that his relationships with others had vastly improved and that he had not found himself in any significant interpersonal conflict since starting treatment. 
On the topic of alcohol, Tommy said, "I feel like I have it more under control. I appreciate that you didn't just come at me and tell me I had to quit drinking altogether. I'm just happy that I could learn some new skills that kept me out of trouble." I inquired about how Tommy felt about our discussions about masculinity. He said, "That was the biggest surprise of this experience because I never thought that it would be something you'd focus on in therapy." Tommy indicated that these discussions were "eye-opening" and made him look at males around him differently. He said, "It also made me think a little bit more about why I think and act the way I do and question what's really important for me now and in the future."

Tommy stated that he wished he had more time in therapy with me because there were still outstanding issues that he felt needed to be addressed. When asked what he felt like we neglected, he indicated that he wished we had spent more time processing his breakup with his girlfriend and his difficult relationship with his father. Tommy said, "I also wish I had more time to explore what I want out of my next relationship. I haven't been going about that the right way and feel like I could use some more skills in that area." Admittedly, I had not spent enough time on these subjects out of my desire to address his alcohol use, depressive symptoms, and internalized masculinity norms. As it stood, 16 sessions was not even enough time to fully cover those three domains in enough depth, and I felt as though I had somewhat overpacked his course of treatment.

Tommy expressed some concern that his depression would come back over the summer, especially if he ran into his ex-girlfriend. I asked him what he thought he would do to prevent himself from falling back into the same habits as before. Tommy stated that he would avoid excessive social media use, continue to utilize harm reduction techniques for moderating alcohol use, try to spend more time around other people than alone, and keep scheduling rewarding activities for himself. He indicated that ongoing exercise was important for him, both in terms of mitigating the biological effects of stress and maintaining a healthy self-esteem. Tommy reported that he was also more open to asking for help than before and was looking forward to spending more time with his mother this summer and asking for her support if needed.

Tommy was in an upbeat and optimistic mood during session \#16, our final session. He stated that he was feeling excited to go home for the summer to spend time with his mother and high school friends. Tommy indicated that he wanted to get a job to stay busy and stated that he was going to look into becoming a camp counselor. He continued to voice concerns about running into Ashley around town but recognized that he needed to live in the moment and not just worry about what could happen. Tommy reported that he was optimistic about managing his alcohol intake back home because he would not be around as many parties and believed that his high school friends would be even more understanding than his college friends had been.

I used this final session to review and summarize the treatment gains Tommy had made over the past four months. I highlighted how, based on outcome measures, his self-reports, and how he presented in treatment, his depressive symptoms had vastly reduced since the start of therapy. Although he still experienced a low mood, sleeping difficulties, and some self-esteem concerns from time to time, this was expected for someone who was coping with difficult changes in their lives. I explained that depression did not simply disappear and that it often took 
time to dissipate. I also discussed how Tommy might experience depression on and off throughout his life and that it was not something he should expect to overcome all at once.

In addition to his successful efforts to mitigate depressive symptoms, I also underscored how committed Tommy had been to cutting back on his alcohol intake and avoiding negative consequences that could result from drinking. On this topic, he said,

'It's been hard but I am proud of what I've been able to do. It's made it easier not looking at it as getting wasted or not drinking at all and realizing that I could have a drink or two from time to time. I think I needed to prove that I could have some self-control.”

I reminded him of some of the strategies that he had used to stay safe (e.g., determining how many drinks he would have before he started drinking) and how beneficial it had been for him to recruit his friends in helping him stay on track.

We also discussed how Tommy had been able to successfully explore his masculine identity and reflect on his adherence to traditional norms and consider where they had originated. Because Tommy was not overly adherent to these values, he had been able to become more mindful of his beliefs and behaviors and consider how they were impacting his choices, relationships, and ability to seek help. Tommy said, "I keep thinking about how guys get in their own way so much of the time and can be so stubborn. They create their own problems and refuse to let anyone help them out of them." The fact that Tommy had been open to considering how he had internalized traditional masculinity norms and was not particularly defensive made it easier to explore such concepts and help him consider other ways of seeing and interacting with the world around him. I was hopeful that Tommy would be open to discussing his feelings and asking for help in the future, leading to deeper, more satisfying relationships.

I encouraged Tommy to continue to be mindful of his social media usage and other vegetative and isolative activities when he left campus for the summer. Since the summer months were often less structured than a collegiate semester, I cautioned him that such downtime could create the potential for more mindless activities, which, in turn, could negatively impact his mood. Instead, I urged him to schedule his days purposefully and budget in both productive and rewarding activities that would increase and maintain his self-esteem and feelings of competency and mastery. Tommy replied, "My family has a membership to a gym, so I'll make sure to get a lot of exercise. Getting a job will also help. My friends and I have also been texting about planning a number of outings, so I'm hoping to keep busy." Tommy stated that he also had a weeklong vacation to Cape Cod planned with his mother and grandparents.

I took a moment to praise Tommy for his commitment to attending and taking ownership of his treatment throughout the semester. I marveled at his change in attitude towards therapy over the months and reminded him that the gains that he experienced from treatment were only possible because he had worked hard, trusted another person to help him, and taken chances, even when it felt uncomfortable. This willingness was indicative of a flexible masculinity and provided me with hope that Tommy would continue to make positive changes as he advanced in his academic career and beyond. 
When I alerted Tommy that we would need to end the session, he smiled anxiously and let out a big sigh. He said, "This is harder than I thought it would be. I knew we would have to end but it still feels sort of incomplete. I feel like I have more to work on in therapy."

I agreed that Tommy could probably benefit from ongoing therapy but was in a good place to take some time off and reconsider his needs over the summer. I also acknowledged how treatment starts and stops were often artificially determined by the logistics of the setting and that it could be frustrating.

Tommy stated that he hoped to return to the counseling center in September because he enjoyed having an hour a week to process his thoughts and work on new skills. He expressed some sadness that I would not be in the counseling center next year but was hopeful that someone else on the staff could continue to guide him towards a healthier way of living. I wished Tommy the best of luck and encouraged him to keep up the good work over the summer, reminding him that he could always seek therapeutic help in the community if he felt overwhelmed.

\section{THERAPY MONITORING AND USE OF FEEDBACK}

During the course of Tommy's treatment, I received one hour of weekly individual supervision from a licensed clinical psychologist. Our supervision consisted of conversations about my clinical work with Tommy, as well as listening to relevant portions of audio recordings taken each session with the client's consent. Throughout our discussions, my supervisor actively helped me select appropriate interventions and decide when it was a good time in treatment to shift focus from one presenting concern to another. My supervisor also gave me space to address any "countertransference" reactions that I was personally experiencing while working with Tommy.

In addition to individual supervision, I also had one hour of group supervision each week with the same supervisor, two other practicum students, and a predoctoral intern. Group supervision offered the opportunity to receive greater perspective and feedback in regards to my work, especially since each of the trainees brought a unique theoretical orientation to supervision.

Throughout Tommy's therapy, I also continuously provided him with three quantitative measures: the Outcome Questionnaire-45 (OQ-45), Patient Health Questionnaire-9 (PHQ-9), and Meaning of Adolescent Masculinity Scale (MAMS). Tommy completed the OQ-45 and PHQ-9 every third session beginning at his intake, while he completed the MAMS every third session starting at session \#4. These three measures helped my supervisor and me measure therapy progress and determine whether I needed to adjust the focus of our sessions or the overall treatment plan. At times, I also used the results of these measures to facilitate discussion in our sessions and to ask Tommy if he felt as though his responses accurately mirrored his actual progress and change in level of functioning. Furthermore, I felt as though completing these measures helped Tommy reflect on his behaviors, thoughts, and emotions and gave him an additional reminder of some of the major benchmarks of his treatment goals. 


\section{CONCLUDING EVALUATION OF THE THERAPY'S PROCESS AND OUTCOME}

\section{The Outcome of Tommy's Therapy}

The quantitative and qualitative data (see below) from Tommy's case suggest a moderately positive treatment outcome. Given the short-term, semester-long nature of his treatment, it was expected that there would still be room for further growth at the time of termination. Despite the time-limited nature of treatment and Tommy's initial hesitance to engage in the sessions, he eventually committed himself to his therapy and took enough ownership of the process to make positive changes in various domains of his life.

\section{Quantitative Results}

Table 1 presents Tommy's OQ-45 scores throughout treatment. During his intake, Tommy's scores on the Total, Symptom Distress, Interpersonal Relationships, and Social Role scales were all above the clinical cut-off points. Between when the measure was administered at the start of session \#7 and the start of session \#10, Tommy dropped below clinical cut-off points on all scales except for the Symptom Distress Score scale. He subsequently dropped below this scale during the next administration of the measure. By the end of treatment, he was below the clinical cut-off points on all four scales.

Table 2 presents Tommy's PHQ-9 scores throughout treatment. At the start of treatment, Tommy initially scored a 16 on the measure, putting him into the category of moderately severe depression (as categorized by scores of 15-19). After his initial session, Tommy's scores on this measure were in the moderate depression range (as categorized by scores of 10-14) for sessions 4-10. Towards the end of treatment, his scores on this measure had dropped into the mild range (as categorized by scores of 5-9), indicating significant improvement despite some remaining symptoms.

Table 4 presents Tommy's MAMS scores throughout treatment. The possible range of scores on the MAMS is 27-108, with 27 indicating little to no adherence to traditional masculinity norms as they pertain to Constant Effort, Emotional Restriction, Heterosexism, and Social Teasing, and 108 signifying rigid alignment with these beliefs and values. To date, there is no information regarding what constitutes a high, moderate, or low score on the total scale or the subscales. In light of this, I used the MAMS as an indicator of the relative degree to which Tommy identified with certain traditional masculinity norms over the course of treatment. During the first three administrations of the measure, Tommy scored moderately high on all four subscales and was fairly consistent in how he answered the questions each time. However, by the time of session \#13, I had provided Tommy with psychoeducation about traditional masculinity norms, and he had begun to explore and reflect on his own beliefs about masculinity. These discussions asked him to consider qualities and attributes that he wanted to enact in his own life and which he wanted to discard. As such, his Total Score and scores on all three subscales were considerably lower when the MAMS was administered in sessions \#13 and \#16. 


\section{Qualitative Results}

As described in Chapter VI (Course of Treatment), Tommy and I summarized and reviewed his treatment progress during the last two sessions of his therapy. The following is a summary of the qualitative results of Tommy's treatment outcomes:

- Tommy was no longer drinking as much alcohol as he had been during the fall semester. During many sessions, he reported that he had not drank alcohol in the last week, while during others, he reported having anywhere between 1-3 drinks a week. Throughout our treatment, Tommy did not incur any further disciplinary violations from residence life staff, refrained from upsetting any of his peers with negative behaviors resulting from drinking, and did not experience any negative physical consequences from drinking, such as vomiting, blacking out, or hangovers. Throughout treatment, Tommy learned harm reduction strategies that could help him minimize negative consequences from drinking and became willing to ask his friends to help him stay on track when he decided not to drink or hold himself to just a few drinks in an evening.

- $\quad$ Tommy was no longer reporting many depressive symptoms at the end of treatment. Although he still reported some occasional nighttime sadness and intermittent difficulty falling asleep, he no longer endorsed anhedonia, concentration difficulties, increased appetite, weight gain, excessive daytime sleeping, or fatigue. While he still struggled with his self-esteem in some domains, his presentation at the end of treatment was vastly different than the palpable sense of worthlessness he addressed at his intake. Tommy was also exhibiting far less anger and irritability than he had been at the beginning of treatment. By termination, he demonstrated more hopefulness and excitement about the future that lay before him.

- Through behavioral activation, Tommy had gained a better understanding of how he benefited from being active and engaged with his environment, especially when it came to taking part in activities in which he could exhibit mastery. He recognized that solitary, vegetative activities such as napping, endless social media, and drinking alone in his room contributed to negative emotions, despite serving as short term escapes. Tommy came to understand the benefit of scheduling rewarding activities each day to create room for selfcare and reinforce himself for attending to more obligatory, less enjoyable tasks.

- Tommy was becoming more aware of his automatic thoughts and how they related to core beliefs that he held about himself. Although he reported that he did not enjoy cognitive restructuring, he demonstrated that he was capable of identifying his thoughts, stating how they made him feel, and formulating more adaptive and realistic thoughts in response. By the end of treatment, Tommy was cognizant of situations that were likely to bring about negative automatic thoughts (e.g., looking at his ex-girlfriend's social media profile) and was able to recognize the categories of cognitive distortions he was most likely to utilize (e.g., catastrophizing and fortune-telling).

- Tommy was attending all of his classes by the end of treatment. While he had not been happy with his grades at the end of the fall semester, at the time of termination, he reported 
that he was likely to receive 3 As and 2 Bs for the spring semester. He was completing assignments on time and had been willing to communicate his earlier difficulties to his professors in order to receive extensions on some assignments.

- Tommy had become more physically active by the end of treatment. He was regularly going to the gym and understood that his workouts had a positive physiological effect on his mood, while also improving his self-esteem. Tommy also reported pride about being able to push himself back into an exercise routine even when he did not feel like leaving his dorm, a sentiment very much in the spirit of "acting as if."

- Tommy received psychoeducation about traditional masculinity norms and how they can be detrimental to one's health, quality of interpersonal relationships, academic and career prospects, and basic areas of daily functioning when rigidly enacted. He was able to consider the sources from which these messages had originated in his life and reflect on how these norms were reinforced and internalized over the years.

- Tommy began the process of redefining his masculine identity in more flexible terms rather than maintaining IE-TMNs. He now recognized the benefits of seeking help from others, disclosing his emotions, and allowing himself to vulnerably grieve without needing to externalize his feelings through drinking, hookups, or aggressive encounters with others. Tommy understood that this identity reconstruction did not mean disavowing all qualities considered masculine. Rather, he had the opportunity to pick and choose which qualities were actually important to him versus those to which he felt pressured to adhere.

- $\quad$ Tommy recognized the value of therapy by the end of the semester. Although he had initially been hesitant to engage in the process and was embarrassed to be mandated to treatment, he demonstrated a willingness to make the best of the situation and consider how he could use it to alleviate his suffering. I believe this experience painted a positive picture of therapy for him and made it more likely that he would return to treatment in the future if he felt the need.

\section{Results in the Context of the Original Treatment Plan}

According to the quantitative and qualitative results detailed above, it would appear as

though Tommy met all of the treatment goals originally outlined in Chapter V (Case Formulation and Treatment Plan):

GOAL 1: Provide rationale for treatment, establish rapport, and create a safe, validating, and nonjudgmental environment.

GOAL 2: Decrease Tommy's alcohol consumption through harm reduction and motivational interviewing strategies.

GOAL 3: Provide Tommy with psychoeducation about the relationship between substance use and depression.

GOAL 4: Decrease depressive symptoms on PHQ-9 to at least mild range $(<10)$. 


\section{GOAL 5: Provide Tommy with psychoeducation about traditional masculinity norms.}

GOAL 6: Decrease Tommy's MAMS score by helping him construct his own definition of masculinity.

GOAL 7: Decrease Tommy's overall distress level based on achieving a "less than clinical | significance" range score on the $O Q-45$.

GOAL 8: Review treatment gains, coping skills, and relapse prevention strategies.

Ultimately, Tommy was able to make significant changes throughout his course of treatment. Compared to the prior semester, he was drinking far less alcohol and had not experienced any negative consequences from his drinking. Tommy's depressive symptoms had also considerably decreased and he was making a concerted effort to avoid vegetative and isolative activities, such as excessive sleeping or social media activity. Due to these changes, he was attending classes more often, completing more of his assignments and receiving higher grades, spending more time with friends, and not reporting any interpersonal conflict. Tommy had also begun the process of reflecting on his masculine identity and reshaping it based on his own beliefs, values, and goals. He was now more aware of the pitfalls of IE-TMNs and appeared open to enacting a more flexible definition of masculinity, as evidenced by his willingness to seek help, express a variety of emotions, and strengthen his relationship with his mother.

Tommy's general distress level decreased throughout treatment and he reported greater overall life satisfaction. These treatment gains were largely possible because of Tommy's willingness to form a meaningful therapeutic bond with me and trust me enough to help him with major stressors in his life.

\section{Discussion of Broader Issues Raised by Tommy's Case.}

The case of Tommy serves as one example of how it can be important to explore and discuss the impact of inflexibly enacted traditional masculinity norms (IE-TMNs) in therapy when working with depressed adolescent and young adult males. This particular case study is just one example of what it might be like to address these themes in treatment and will not be representative of all other individuals struggling with their masculine identity. While Tommy's experience captures many of the key themes of IE-TMNs, the ways in which different clients will present in treatment in regards to these issues will vary by developmental stage, race and ethnicity, sexual orientation, location, religion, and other important identity characteristics. Additionally, experiences will also differ based on the extent to which the client subscribes to traditional masculinity norms at the start of treatment. Although Tommy had internalized many of these beliefs over the years and endorsed a number of traditional beliefs and attitudes, he was also open to reflecting on his behaviors and values and did not become overly defensive when I asked him to consider how they impacted his presenting concerns. A client who was more entrenched in these beliefs and held them sacred would certainly not progress through treatment in quite the same way as Tommy.

Reflecting on the case, it is also important to consider how my work with Tommy was shaped by the fact that I was a male therapist. In many ways, I believe that my ability to model a more flexible masculinity benefited him. Through our interactions, I gave him the opportunity to 
experiment with asking for help, to discuss his emotions, and to exhibit vulnerability with another male figure. While he may have been more immediately comfortable with a female therapist, in my clinical judgment, I don't believe the masculinity-related discussions would have been as productive for him in that situation. In any event, this case is an important example of how therapist characteristics are necessary to consider when determining best fit for a certain client with a particular set of presenting concerns.

The hybrid case study research design holds many advantages for exploring an issue like the relationship between masculinity norms and depression. By combining relevant clinical examples from the literature and personal accounts of working with specific clients, one is able to explore myriad themes and concepts that might be more restricted when describing the experiences of one individual. The hybrid case study also obscures each client's identifying information and personal experiences, preserving confidentiality and privacy in general. Through use of a hybridized client that combines the experiences of multiple individuals, one is able to describe and discuss how particular issues can be addressed in treatment using particular interventions from relevant theoretical lenses. This course of treatment can serve to build on the existing knowledge of how to work with depressed adolescent and young adult males in therapy.

While there are many benefits to this method of inquiry, there are limitations to the hybrid case study research design as well. Since the hybridized individual is representing the experiences of a variety of different clients, the unique individual detail and contextual factors that are present when describing a single real life cases study are diminished. Similarly, although the hybrid case design allows for the opportunity to conveniently discuss many relevant themes that an individual could bring to treatment related to a particular issue, it may overemphasize how immediately observable such issues might be for a clinician. Lastly, the use of fictionalized quantitative measures can feel artificial and arbitrary, even when the results might be mirroring real life data gathered when utilizing the same questionnaires.

I hope that this case study demonstrates the need to pay greater attention to how we work with young boys and men in treatment and consider how their gender identity influences and impacts their presenting concerns. In many cases, clinicians fail to recognize depression in boys and men because of the manner in which their symptoms manifest. Subsequently, the field often fails to provide appropriate treatment to these individuals and the issues persist. As traditional masculinity norms are introduced, reinforced, policed, and internalized at a very young age, it is crucial for mental health practitioners, teachers, medical providers, parents, and anyone else in a role of authority to endorse and model more flexible and adaptive ideas of masculinity. I believe that it would be beneficial to take a prevention approach to the issue and socialize boys in a way that emphasizes emotional expression, vulnerability, and help-seeking behaviors in much the same way that girls are taught to behave from a young age.

Having immersed myself clinically in this area, I would like to end with my own observations on how the issue of masculinity is viewed in American society at large. The topic of IE-TMNs and their detrimental impact to society is becoming more widely addressed in the modern zeitgeist. Many youth communities are becoming more accepting toward how one defines their gender identity and sexual orientation, making it easier for boys and young men in some environments to openly question traditional gender norms without fear of ostracization or 
retaliation. Additionally, the need for a more expansive definition of masculinity is positively highlighted in movies, television, internet articles, and other forms of mass media, even as our current president serves as a looming depiction of the dangers of rigid adherence to traditional beliefs and values. One recent example of the need for more progress in this area is the public's mixed reaction to a 2019 commercial by Gillette, in which masculine strength was redefined as being sensitive and caring for others (for the commercial, see:

https://www.youtube.com/watch? $\mathrm{v}=\mathrm{koPmuEyP} 3 \mathrm{a} 0$; for a commentary on the advertisement and its intended purpose see: https:/www.wired.com/story/gillette-we-believe-ad-men-backlash/; and for the public's mixed reaction, see: https://www.thecut.com/2019/01/gillette-the-best-mencan-be-commercial-backlash.html).

In the present moment, I also believe that the frequent usage of the term "toxic masculinity" by more liberal-leaning individuals introduces its own set of drawbacks. While used in an attempt to highlight behaviors and attitudes that can be destructive to society, this term is largely deployed pejoratively to criticize others and, in effect, has led many to automatically associate the term "masculinity" with maladaptive qualities. As reflected in my presentation of the case of Tommy, rather than fight "toxic masculinity," I believe it would be better to stress developing "healthy masculinity" in order to highlight the positives of identity exploration and reconstruction and emphasize that there are many positive characteristics of masculinity that can be beneficial in moderation. As these public conversations continue to take place, my hope is that the field of psychology will take a greater role in addressing such concerns and integrating these themes into our work with boys and men to foster a healthier, more adaptive and flexible set of beliefs and behaviors.

\section{REFERENCES}

Addis, M.E. \& Mahalik, J.R. (2003). Men, masculinity, and the contexts of help-seeking. American Psychologist, 58(1), 5-14.

Addis, M. E. (2008). Gender and depression in men. Clinical Psychology: Science and Practice, 15(3), 153-168.

Addis, M.E. \& Martell, C.R. (2004). Overcoming depression one step at a time: The new behavioral activation approach to getting your life back. Oakland: New Harbinger Publications, Inc.

American Psychiatric Association. (2013). Diagnostic and statistical manual of mental disorders ( $5^{\text {th }}$ ed.). Washington, DC: Author.

American Psychological Association, Boys and Men Guidelines Group. (2018). APA guidelines for psychological practice with boys and men. Retrieved from https://www.apa.org/about/policy/boys-men-practice-guidelines.pdf

Beck, J.S. (2011). Cognitive behavior therapy: Basics and beyond. New York: The Guilford Press.

Boden, J.M. \& Fergusson, D.M. (2011). Alcohol and depression. Addiction, 106, 906-914.

Bronfenbrenner, U. (1979). The ecology of human development. Cambridge: Harvard University Press.

Brown, F.C., Buboltz Jr., W.C., \& Soper, B. (2002). Sleep hygiene practices and sleep quality in university students. Behavioral Medicine, 28(1), 33-38. 
C. Dewey

Pragmatic Case Studies in Psychotherapy, http://pcsp.libraries.rutgers.edu

Volume 16, Module 3, Article 1, pp. 237-304, 12-28-20 [copyright by author]

Cerón, E. (2019, January 15). MRAs outraged after razor company asks men to show common decency. The Cut. https://www.thecut.com/2019/01/gillette-the-best-men-can-becommercial-backlash.html

Courtenay, W. H. (2000). Constructions of masculinity and their influence on men's well-being: a theory of gender and health. Social Science \& Medicine, 50(10), 1385-1401.

Craig, S. (1992). Men, masculinity, and the media. London: SAGE Publications. de Vries, D.A., Peter, J., de Graaf, H., \& Nikken, P. (2016). Adolescents' social network site use, peer appearance-related feedback, and body dissatisfaction: Testing a mediation model. Journal of Youth and Adolescence, 45(1), 211-224.

de Vries, D. A., Peter, J., Nikken, P., \& de Graaf, H. (2014). The effect of social network site use on appearance investment and desire for cosmetic surgery among adolescent boys and girls. Sex Roles, 71(9-10), 283-295.

Dewey, C. (2020). Inflexibly enacted traditional masculinity norms (IE-TMNs) and their impact on adolescent and young adult depression: The hybrid case study of "Tommy". Unpublished doctoral dissertation, Rutgers University, Piscataway, NJ.

Diamond, L.M. (2013). Sexual-minority, gender-nonconforming, and transgendered youths. In Bromberg, D.S., \& O’Donohue, W.T. (Eds.) Handbook of child and adolescent sexuality:Developmental and forensic psychology (pp. 275-300). Oxford: Academic Press.

Dreyfuss, E. (2019, Jan 16). Gillette's ad proves the definition of a good man has changed. Wired. https://www.wired.com/story/gillette-we-believe-ad-men-backlash/

Eisler, R.M., Skidmore, J.R., \& Ward, C.H. (1988). Masculine gender-role stress: Predictor of anger, anxiety, and health-risk behaviors. Journal of Personality Assessment, 52(1), 133141.

Emslie, C., Ridge, D., Ziebland, S., \& Hunt, K. (2006). Men's accounts of depression: Reconstructing or resisting hegemonic masculinity? Social Science \& Medicine, 62(9), 2246-2257.

Fishman, D.B. (1999). The case for pragmatic psychology. New York: New York University Press.

Fishman, D. B. (2013). The pragmatic case study method for creating rigorous and systematic, practitioner-friendly research. Pragmatic Case Studies in Psychotherapy, 9(4), Article 2, 403-425. Available: http://pcsp.libraries.rutgers.edu/

Gillette. (2019, Jan 13). We believe: The best men can be. [Video]. YouTube. https://www.youtube.com/watch? $=$ koPmuEyP3a0

Graham, J.W., Tatterson, J.W., Roberts, M.M., Johnston, S.E. (2004). Preventing alcohol-related harm in college students: Alcohol-related harm prevention program effects on hypothesized mediating variables. Health Education Research, 19(1), 71-84.

Hankin, B. L. (2006). Adolescent depression: description, causes, and interventions. Epilepsy \& Behavior, 8(1), 102-114.

Hankin, B. L., Mermelstein, R., \& Roesch, L. (2007). Sex differences in adolescent depression: Stress exposure and reactivity models. Child Development, 78(1), 279-295.

Kim, J. W., \& Chock, T. M. (2015). Body image 2.0: Associations between social grooming on Facebook and body image concerns. Computers in Human Behavior, 48, 331-339.

Kroenke, K., Spitzer, R. L., \& Williams, J. B. (2001). The PHQ-9: Validity of a brief depression severity measure. Journal of General Internal Medicine, 16(9), 606-613. 
Lambert, M. J., Gregersen, A. T., \& Burlingame, G. M. (2004). The Outcome Questionnaire-45. In M. E. Maruish (Ed.), The use of psychological testing for treatment planning and outcomes assessment: Instruments for adults (pp. 191-234). Mahwah, NJ, US: Lawrence Erlbaum Associates Publishers.

Leahy, R.L., Holland, S.J.F., \& McGinn, L.K. (2012). Treatment plans and interventions for depression and anxiety disorders. New York: The Guilford Press.

LeMarquand, D., Pihl, R.O., \& Benkelfat, C. (1994). Serotonin and alcohol intake, abuse, and dependence: Clinical evidence. Biological Psychiatry, 36(5), 326-337.

Li, C.E., DiGiuseppe, R., \& Froh, J. (2006). The roles of sex, gender, and coping in adolescent depression. Adolescence, 41(163), 409-415.

Liu, W.M, Rochlen, A., \& Mohr, J.J. (2005). Real and ideal gender-role conflict: Exploring psychological distress among men. Psychology of Men \& Masculinity, 6(2), 137-148.

Mahalik, J.R., Burns, S.M., \& Syzdek, M. (2007). Masculinity and perceived normative health behaviors as predicators of men's health behaviors. Social Science \& Medicine, 64(11), 2201-2209.

Mahalik, J.R., Good, G.E., \& Englar-Carlson, M. (2003). Masculinity scripts, presenting concerns, and help-seeking: Implications for practice and training. Professional Psychology: Research and Practice, 34(2), 123-131.

Mahalik, J. R., Good, G. E., Tager, D. T., Levant, R. F., \& Mackowiak, C. (2012). Developing a taxonomy of helpful and harmful practices for clinical work with boys and men. Journal of Counseling Psychology, 59, 591-603.

Mahalik, J.R., Levi-Minzi, M., \& Walker, G. (2007). Masculinity and health behaviors in Australian men. Psychology of Men \& Masculinity, 8(4), 240.

Mahalik, J.R. \& Rochlen, A.B. (2006). Men's likely responses to clinical depression: What are they and do masculinity norms predict them? Sex Roles, 55, 659-667.

Mahalik, J.R., Lombardi, C.M., Sims, J., Coley, R.L., \& Lynch, A.D. (2015). Gender, maletypicality, and social norms predicting adolescent alcohol intoxication and marijuana use. Social Science and Medicine, 143, 71-80.

Martin, L.A., Neighbors, H.W., Griffith, D.M. (2013). The experience of symptoms of depression in men vs. women: Analysis of the National Comorbidity Survey Replication. JAMA Psychiatry, 70(10), 1100-1106.

Mayo Clinic (2016). Depression [Data file]. Retrieved from http://www.mayoclinic.org/diseasesconditions/depression/basics/definition/con-20032977

McWilliams, N. (2004). Psychoanalytic psychotherapy. New York: The Guilford Press.

Meth, R.L. \& Pasick, R.S. (1990). Men in therapy: The Challenge of Change. New York: The Guilford Press.

Monroe, S.M. \& Simons, A.D. (1991). Diathesis-stress theories in context of life stress research implications for the depressive disorders. Psychological Bulletin, 110(3), 406-425.

National Institute of Mental Health (2003). Depression in men: Real men, real depression [Data file]. Retrieved from http://www.nimh.nih.gov/health/topics/depression/men-anddepression/depression-in-men.html

Neighbors, C., Larimer, M.E., Lostutter, T.W., \& Woods, B.A. (2006). Harm reduction and individually focused alcohol prevention. International Journal of Drug Policy, 17(4), 304-309. 
Norcross, J.C., Wampold, B.E., \& Lambert, M.J. (Eds.) (2019). Psychotherapy relationships that work, 2 vol set, 3rd edition. New York: Oxford University Press.

Oransky, M. \& Fisher, C. B. (2009). The development and validation of the Meanings of Adolescent Masculinity Scale. Psychology of Men \& Masculinity, 10, 57-72

Persons, J.B. (2008). The case formulation approach to cognitive-behavior therapy. New York: The Guilford Press.

Pollack, W.S. (1998). Real boys. New York, NY: Owl Books.

Pollack, W. S. (2006). The "war" for boys: Hearing "real boys"' voices, healing their pain. Professional Psychology: Research and Practice, 37(2), 190-195.

Reidy, D.E., Smith-Darden, J.P., Vivolo-Kantor, A.M., Malone, C.A., \& Kernsmith, P.D. (2018). Masculine discrepancy stress and psychosocial maladjustment. Psychology of Men \& Masculinity, 19(4), 560-569.

Reigeluth, C.S. \& Addis, M.E. (2010). Pragmatic clinical research to inform the field of men's mental health: A commentary on and extension of papers by David Edward \& Tracy Eells. Pragmatic Case Studies in Psychotherapy, 6(4), Article 7, 307-314. Available: http://pcsp.libraries.rutgers.edu/

Reigeluth, C.S. \& Addis, M.E. (2016). Adolescent boys' experiences with policing of masculinity: Forms, functions, and consequences. Psychology of Men \& Masculinity, 17(1), 74-83.

Rogers, C. R. (1961). On becoming a person. Boston: Houghton Mifflin Company.

Rutledge, C. M., Gillmor, K. L., \& Gillen, M. M. (2013). Does this profile picture make me look fat? Facebook and body image in college students. Psychology of Popular Media Culture, 2(4), 251.

Seidler, Z.E., Dawes, A.J., Rice, S. M., Oliffe, J.L., \& Dhillon, H.M. (2016). The role of masculinity in men's help-seeking for depression: A systematic review. Clinical Psychology Review, 49, 106-118.

Tifferet, S., \& Vilnai-Yavetz, I. (2014). Gender differences in Facebook self-presentation: An international randomized study. Computers in Human Behavior, 35, 388-399.

Van den Wijngaard, M. (1997). Reinventing the sexes: The biomedical construction of femininity and masculinity. Bloomington: Indiana University Press.

Ward, L. M., Merriwether, A., \& Caruthers, A. (2006). Breasts are for men: Media, masculinity ideologies, and men's beliefs about women's bodies. Sex Roles, 55(9-10), 703-714.

World Health Organization. (2016). Depression [Data file]. Retrieved from http://www.who.int/mediacentre/factsheets/fs369/en 
Table 1. Tommy's Scores on the Outcome Questionnaire-45 (OQ-45) Scale

\begin{tabular}{|c|c|c|c|c|}
\hline Session Number & Total Score+ & $\begin{array}{c}\text { Symptoms } \\
\text { Distress Score+ }\end{array}$ & $\begin{array}{c}\text { Interpersonal } \\
\text { Relations Score+ }\end{array}$ & $\begin{array}{c}\text { Social Role } \\
\text { Score+ }\end{array}$ \\
\hline 1 & $80^{*}$ & $41^{*}$ & $21^{*}$ & $18^{*}$ \\
\hline 4 & $74^{*}$ & $40^{*}$ & $17^{*}$ & $17^{*}$ \\
\hline 7 & $68^{*}$ & $40^{*}$ & $15^{*}$ & $13^{*}$ \\
\hline 10 & 59 & $36^{*}$ & 13 & 10 \\
\hline 13 & 46 & 27 & 10 & 9 \\
\hline 16 & 40 & 24 & 8 & 8 \\
\hline
\end{tabular}

* Score is indicative of symptoms and/or impaired functioning that are above the clinical cut-off point as noted by Lambert, Morton, Hatfield, Harmon, Hamilton, Reid, Shimokawa, Christopherson, and Burlingame (2004) in the Administration and Scoring Manual for the OQ45.2 (Outcome Questionnaire).

+ Clinical cut-off scores are the following: Total Score of 63 or above; Symptom Distress Score of 36 or above; Interpersonal Relations Score of 15 or above; and Social Role Score of 12 or above (Lambert et al., 2004).

Table 2. Tommy's Scores on the Patient Health Questionnaire-9 Scale

\begin{tabular}{|c|c|c|}
\hline Session Number & Score & Score Categorization* \\
\hline 1 & 16 & Moderately severe \\
\hline 4 & 14 & Moderate \\
\hline 7 & 12 & Moderate \\
\hline 10 & 11 & Moderate \\
\hline 13 & 8 & Mild \\
\hline 16 & 5 & Mild \\
\hline
\end{tabular}

*Score categorization as noted by Kroenke, Spitzer, \& Williams (2001) 
C. Dewey

Pragmatic Case Studies in Psychotherapy, http://pcsp.libraries.rutgers.edu

Volume 16, Module 3, Article 1, pp. 237-304, 12-28-20 [copyright by author]

Table 3. Copy of the Meanings of Adolescent Masculinity Scale (MAMS), p. 1

\section{Meanings of Adolescent Masculinity Scale \\ (C) 2009 by Oransky \& Fisher}

Oransky, M. \& Fisher, C. B. (2009). The development and validation of the Meanings of Adolescent

Masculinity Scale. Psychology of Men \& Masculinity, 10, 57-72.

Directions Below are statements about masculinity that boys generally agree or disagree with. Using the scale below, please check the box that indicates how much you disagree or agree with the statements. There are NO WRONG answers. Please read each statement carefully and remember that NO ONE will know your answers.

\begin{tabular}{|c|c|c|c|c|}
\hline Statement & \multirow[t]{2}{*}{$\begin{array}{l}\text { Strongly } \\
\text { Disagree }\end{array}$} & \multirow[t]{2}{*}{ Disagree } & \multirow[t]{2}{*}{ Agree } & \multirow[t]{2}{*}{$\begin{array}{c}\text { Strongly } \\
\text { Agree }\end{array}$} \\
\hline $\begin{array}{l}\text { 1. It is normal for guys to make fun of their } \\
\text { friends. }\end{array}$ & & & & \\
\hline $\begin{array}{l}\text { 2. A guy should be embarrassed to "run like a } \\
\text { girl." }\end{array}$ & & & & \\
\hline $\begin{array}{l}\text { 3. If a guy is upset about something, he should } \\
\text { hold it in. }\end{array}$ & & & & \\
\hline $\begin{array}{l}\text { 4. A guy should never back down from a } \\
\text { challenge in public }\end{array}$ & & & & \\
\hline $\begin{array}{l}\text { 5. A good way to seem manly is to avoid acting } \\
\text { gay. }\end{array}$ & & & & \\
\hline $\begin{array}{l}\text { 6. When a guy has a fear, he should keep it to } \\
\text { himself. }\end{array}$ & & & & \\
\hline $\begin{array}{l}\text { 7. A guy who wears nail polish is hard to take } \\
\text { seriously. }\end{array}$ & & & & \\
\hline $\begin{array}{l}\text { 8. Guys should try to appear manly in almost } \\
\text { all situations. }\end{array}$ & & & & \\
\hline 9. Guys do NOT pick on each other to be mean. & & & & \\
\hline $\begin{array}{l}\text { 10. It is weird for a guy to talk about his } \\
\text { feelings with other guys. }\end{array}$ & & & & \\
\hline $\begin{array}{l}\text { 11. In order to fit in, guys must be able to tease } \\
\text { other guys. }\end{array}$ & & & & \\
\hline $\begin{array}{l}\text { 12. It is NOT important for guys to listen to each } \\
\text { other's problems. }\end{array}$ & & & & \\
\hline $\begin{array}{l}\text { 13. No matter what happens, a guy should seem } \\
\text { strong to others }\end{array}$ & & & & \\
\hline $\begin{array}{l}\text { 14. Being thought of as gay makes a guy seem } \\
\text { like less of a man. }\end{array}$ & & & & \\
\hline $\begin{array}{l}\text { 15. A guy must always appear confident even if } \\
\text { he isn't }\end{array}$ & & & & \\
\hline
\end{tabular}


Table 3. Copy of the Meanings of Adolescent Masculinity Scale (MAMS), p. 2

\begin{tabular}{|c|c|c|c|c|}
\hline Statement & $\begin{array}{l}\text { Strongly } \\
\text { Disagree }\end{array}$ & Disagree & Agree & $\begin{array}{l}\text { Strongly } \\
\text { Agree }\end{array}$ \\
\hline $\begin{array}{l}\text { 16. There is something wrong if a guy wants to } \\
\text { do activities usually done by girls. }\end{array}$ & & & & 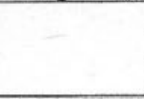 \\
\hline $\begin{array}{l}\text { 17. A guy should be able to take teasing from his } \\
\text { friends. }\end{array}$ & & & & \\
\hline $\begin{array}{l}\text { 18. It is NOT a guy's job to comfort a friend who } \\
\text { is upset. }\end{array}$ & & & & \\
\hline $\begin{array}{l}\text { 19. Acting manly should be the most important } \\
\text { goal for guys. }\end{array}$ & & & & \\
\hline $\begin{array}{l}\text { 20. Getting made fun of helps guys become } \\
\text { tough. }\end{array}$ & & & & \\
\hline $\begin{array}{l}\text { 21. A guy should always seem as manly as other } \\
\text { guys that he knows }\end{array}$ & & & & \\
\hline $\begin{array}{l}\text { 22. It would be embarrassing for a guy to admit } \\
\text { he is interested in being a hair dresser. }\end{array}$ & & & & \\
\hline $\begin{array}{l}\text { 23. It is hard to respect a guy who shows his } \\
\text { feelings. }\end{array}$ & & & & \\
\hline $\begin{array}{l}\text { 24. It is embarrassing to have a lot of gay } \\
\text { friends. }\end{array}$ & & & & \\
\hline $\begin{array}{l}\text { 25. There is nothing wrong with a guy who picks } \\
\text { on his friends }\end{array}$ & & & & \\
\hline $\begin{array}{l}\text { 26. Guys should not talk about their worries with } \\
\text { each other. }\end{array}$ & & & & \\
\hline 27. "Real" guys never act like a girl. & & & & \\
\hline
\end{tabular}

Subscales:

Constant Effort - 4, 8, 13, 15, 19, 20, 21,

Emotional Restriction - 3, 6, 10, 12, 18, 23, 26

Heterosexism - 2, 5, 7, 14, 16, 22, 24, 27

Social Teasing $-1,9,11,17,25$ 
Table 4. Tommy's Scores on the Meanings of Adolescent Masculinity Scale (MAMS)

\begin{tabular}{|c|c|c|c|c|c|}
\hline $\begin{array}{c}\text { Session } \\
\text { Number }\end{array}$ & Total Score & $\begin{array}{c}\text { Constant } \\
\text { Effort Score }\end{array}$ & $\begin{array}{c}\text { Emotional } \\
\text { Restriction } \\
\text { Score }\end{array}$ & $\begin{array}{c}\text { Heterosexism } \\
\text { Score }\end{array}$ & $\begin{array}{c}\text { Social } \\
\text { Teasing } \\
\text { Score }\end{array}$ \\
\hline 4 & 70 & 19 & 18 & 15 & 18 \\
\hline 7 & 66 & 18 & 18 & 14 & 16 \\
\hline 10 & 60 & 16 & 15 & 13 & 16 \\
\hline 13 & 43 & 12 & 10 & 10 & 11 \\
\hline 16 & 38 & 10 & 8 & 10 & 10 \\
\hline
\end{tabular}

Note: See Table 3 for a list of items on the MAMS.

The range of scores is as follows:

Total Score: $27-108$

Constant Effort Score: 7-28

Emotional Constriction Score: 7-28

Heterosexism Score: 8-32

Social Teasing Score: $5-20$

(Oransky \& Fisher, 2009)

Table 5. Tommy's Diagnosis at the Beginning and End of Treatment

\begin{tabular}{|l|c|}
\hline $\begin{array}{c}\text { DSM-5 Diagnosis at } \\
\text { Beginning of Therapy }\end{array}$ & $\begin{array}{c}\text { DSM-5 Diagnosis at End of } \\
\text { Therapy }\end{array}$ \\
\hline$\bullet \quad$ F32.1 Major & $\bullet$ F32.4 Major \\
Depressive Disorder, & Depressive Disorder, \\
Moderate, Single & Single Episode, In \\
Episode & Partial Remission \\
F10.20 Alcohol Use & $\bullet \begin{array}{l}\text { F10.20 Alcohol Use } \\
\text { Disorder, Moderate }\end{array}$ \\
& Disorder, In Early \\
& Remission \\
\hline
\end{tabular}


C. Dewey

Pragmatic Case Studies in Psychotherapy, http://pcsp.libraries.rutgers.edu

Volume 16, Module 3, Article 1, pp. 237-304, 12-28-20 [copyright by author]

\section{Figure 1. Sample Automatic Thought Record by Tommy from Session 9}

\section{AUTOMATIC THOUGHT RECORD}

When you notice your mood getting worse, ask yourself, "What's going through my mind right now?" As soon as possible, fill in the table below.

\begin{tabular}{|c|c|c|c|c|c|}
\hline $\begin{array}{l}\text { Date, } \\
\text { Time }\end{array}$ & Situation & $\begin{array}{c}\text { Automatic Thoughts } \\
\text { (ATs) }\end{array}$ & Emotion/s & Adaptive Responses & Outcome \\
\hline & $\begin{array}{l}\text { - What led to the } \\
\text { unpleasant } \\
\text { emotion? } \\
\text { - What distressing } \\
\text { physical } \\
\text { sensations did } \\
\text { you have? }\end{array}$ & $\begin{array}{l}\text { - What thought/s or } \\
\text { image/s went } \\
\text { through your } \\
\text { mind? } \\
\text { - How much did you } \\
\text { believe the } \\
\text { thought at the }(0- \\
100 \%)\end{array}$ & $\begin{array}{l}\text { What } \\
\text { emotion/s } \\
\text { did you feel } \\
\text { at the time? } \\
\text { How } \\
\text { intense } \\
\text { was the } \\
\text { emotion (0- } \\
100 \%) ?\end{array}$ & $\begin{array}{l}\text { - Which thinking styles } \\
\text { did you engage in? } \\
\text { - Use questions below to } \\
\text { respond to the } \\
\text { automatic thought/s. } \\
\text { - How much do you } \\
\text { believe each response } \\
(0-100 \%) ?\end{array}$ & $\begin{array}{l}\text { - How much do } \\
\text { you now } \\
\text { believe your } \\
\text { ATs }(0- \\
100 \%) ? \\
\text { - What } \\
\text { emotion/s do } \\
\text { you now feel? } \\
\text { At what } \\
\text { intensity? }\end{array}$ \\
\hline & $\begin{array}{l}\text {--Trying to get through a } \\
\text { large amount of reading } \\
\text { for classes* } \\
\text {-- Had a headache, } \\
\text { stomach tightness, and } \\
\text { increased heartrate. }\end{array}$ & $\begin{array}{l}\text { "I'm never going to be able } \\
\text { to get all of this work done } \\
(75 \%) " \\
\text { Evidence: } \\
\text {-- I have put off a lot of work } \\
\text {-- It will be harder to get old } \\
\text { work done on top of current } \\
\text { assignments. }\end{array}$ & $\begin{array}{l}-- \text { Sad }(70 \%) \\
\text {-- Defeated }(60 \%) .\end{array}$ & $\begin{array}{l}\text {-- Fortune-telling; } \\
\text { "It might take me a while, but I } \\
\text { will get this work done over time." } \\
(60 \%) \\
\text { "I'm making progress and have } \\
\text { spoken to my professors. They will } \\
\text { understand if I need a little extra } \\
\text { time." (80\%) } \\
\text { "It's okay if my grades aren't } \\
\text { perfect because I'm working on } \\
\text { my depression." (75\%) }\end{array}$ & $\begin{array}{l}\text {-- Believes original } \\
\text { Automatic Thoughts } \\
\text { (35\%) } \\
\text {-- Current emotions: } \\
\text { Sad }(40 \%) \\
\text { Defeated }(20 \%) \\
\text { Reassured }(50 \%) .\end{array}$ \\
\hline
\end{tabular}

Questions to compose an Adaptive Response: (1) What is the evidence that the automatic thought is true? Not true? (2) Is there an alternative explanation? (3) What's the worst that could happen? What's the best that could happen? What's the most realistic outcome? (4) If a friend were in this situation and had this thought, what would I tell him/her?

* Client's handwriting is typed out for legibility. 